\title{
Parameter estimates of a zero-dimensional ecosystem model applying the adjoint method
}

\author{
Markus Schartau*, Andreas Oschlies, Jürgen Willebrand \\ Institut für Meereskunde an der Universität Kiel Düsternbrooker Weg 20, 24105 Kiel, Germany
}

Received 5 February 1999; received in revised form 1 August 1999

\begin{abstract}
Assimilation experiments with data from the Bermuda Atlantic Time-series Study (BATS, 1989-1993) were performed with a simple mixed-layer ecosystem model of dissolved inorganic nitrogen $(N)$, phytoplankton $(P)$ and herbivorous zooplankton $(H)$. Our aim is to optimize the biological model parameters, such that the misfits between model results and observations are minimized. The utilized assimilation method is the variational adjoint technique, starting from a wide range of first-parameter guesses. A twin experiment displayed two kinds of solutions, when Gaussian noise was added to the model-generated data. The expected solution refers to the global minimum of the misfit model-data function, whereas the other solution is biologically implausible and is associated with a local minimum. Experiments with real data showed either bottom-up or top-down controlled ecosystem dynamics, depending on the deep nutrient availability. To confine the solutions, an additional constraint on zooplankton biomass was added to the optimization procedure. This inclusion did not produce optimal model results that were consistent with observations. The modelled zooplankton biomass still exceeded the observations. From the model-data discrepancies systematic model errors could be determined, in particular when the chlorophyll concentration started to decline before primary production reached its maximum. A direct comparision of measured ${ }^{14} \mathrm{C}$-production data with modelled phytoplankton production rates is inadequate at BATS, at least when a constant carbon to nitrogen $\mathrm{C}: \mathrm{N}$ ratio is assumed for data assimilation. (C) 2001 Elsevier Science Ltd. All rights reserved.
\end{abstract}

\section{Introduction}

The nitrogen cycle can be considered as a necessary prerequisite to modelling the oceanic carbon cycle (Fasham and Evans, 1995). Attempts to understand the relevant biological processes of the

\footnotetext{
* Corresponding author. Tel.: + 49-431-597-3973; fax: + 49-431-565876.

E-mail address: mschartau@ifm.uni-kiel.de (M. Schartau).
} 
nitrogen cycle have led to the development of relatively simple nitrogen-based models of marine ecosystems. Such models were coupled to basin-scale general circulation models of the North Atlantic (Sarmiento et al., 1993; Oschlies and Garcon, 1998, 1999).

The ecosystem model equations contain parameterizations, mostly describing rates. The model solutions strongly depend on the choice of the corresponding biological parameters. Since the model parameters should represent a complex system in a simple way, their appropriate estimate remains a major challenge. Only few parameterizations are based upon measurements, taken in the laboratory and the open ocean. The model parameters are considered to be constant in time. In addition, they need to represent a diversity of individual organisms, which are grouped into compartments of, for example, phytoplankton and herbivorous zooplankton.

Data-assimilation techniques help to identify the optimal parameter values for a given ecosystem model. For indirect estimations of parameter values the inclusion of experimental data and open-ocean observations becomes indispensable. But, as the model complexity increases, eventually the data will not suffice to constrain all model parameters, thereby yielding many mathematically equivalent solutions. Furthermore, it is difficult to distinguish between the errors due to the model equations and those due to the choice of parameter values. After optimization the remaining misfits between observations and the optimal model results can be tested, analysing the plausibility of the applied equations. Evans (1999) suggested that an improvement of plankton models could result from careful investigations of the model-data misfits, and that data assimilation may iteratively help to discover processes that are insufficiently resolved by the model. Our long-term goal is to find a simple model that includes the most prevailing processes for large-scale predictions of biogeochemical fluxes. Such a basic model then could be gradually modified and be extended for local process studies.

The purpose of this paper is to study optimized parameter values (parameter solutions) and their dependence on data availability and model errors. In order to improve model formulations for an oligotrophic province in the North Atlantic Ocean, model errors first need to be identified and eliminated. In this study we started with a simple, nitrogen-based, three-compartment model for the upper mixed layer. We optimized the model parameters using data of the Bermuda Atlantic Time-series Study (BATS) from the years 1989-1993.

\section{Parameter estimation of a marine ecosystem model}

In this section, we present the ecosystem model followed by a brief description of the misfit function, hereafter named cost function. Finally, we focus on the observations that enter the cost function.

\subsection{Theoretical background}

Many different methods for parameter estimation exist, such as statistical and variational analysis methods (e.g. Smedstad and O'Brien, 1991; Navon, 1997). All optimizations are based on the minimization of a cost function. An important aspect for biological modelling is to test the model assumptions for consistency with observations. For that reason it is useful to apply 
strong-constraint assimilation methods that yield optimal model solutions that only depend on the choice of the parameter values.

Harmon and Challenor (1997) tested a Monte Carlo method to recover parameter means and standard errors from the a posteriori probability density function. Although their method was successful, many iterations $\left(\mathrm{O}\left(10^{6}\right)\right)$ were needed to find one optimal set of parameter values. Similarly expensive is a stochastic simulated annealing method that was applied to seek for optimal parameter values of biological models by Matear (1995) and by Hurtt and Armstrong $(1996,1999)$.

Information about the gradients of the cost function greatly reduces the computational time for finding the minimum. The gradients can be computed using the chain rule, applying some perturbation technique (Prunet et al., 1996) or the adjoint technique. The adjoint method is very efficient (particularly for high-dimensional parameter spaces) because it provides a complete gradient vector after a single prognostic model and adjoint model integration. Lawson et al. (1996) introduced the adjoint method for data assimilation in marine ecosystem models. Performing optimizations with synthetically produced data, they investigated the sampling rates that were necessary to recover the model parameter values. Spitz et al. (1998) successfully extended this technique to assimilate BATS data into a pelagic seven-compartment model.

\subsection{The ecosystem model}

\subsubsection{Prognostic equations}

The chosen nitrogen-based ecosystem model has only three state variables, phytoplankton $(P)$, herbivores $(H)$, and dissolved inorganic nitrogen $(N)$, as originally proposed by Evans and Parslow (1985). It resembles the three-compartment model of Fasham (1995) for the upper mixed layer. We only changed the parameterization of the deep nutrient concentration. The model allows the recycling of nutrients via zooplankton (Steele and Henderson, 1992) in addition to the recycling of phytoplankton losses. Herbivore losses as a part of remineralization processes could be fecal pellets or particulate fractions due to sloppy feeding. The remineralization of phytoplankton losses could be referred to as microbial decomposition of suspended particles, the so-called "microbial loop" (e.g., Ducklow, 1983).

Evans and Parslow (1985) introduced an analytical daily integral of the phytoplankton growth that depends on the photosynthetically available irradiance (PAR), mixed-layer depth $(M)$, maximum growth rate $\mu_{\mathrm{m}}$, and the initial slope $\alpha$ of the photosynthesis versus light relation. Their growth function is used in our model.

For the PAR we applied a Beer's law formula with attenuation coefficients due to seawater $\left(\kappa_{\mathrm{w}}\right)$ and chlorophyll $\left(\kappa_{\mathrm{c}}\right)$. Both attenuation coefficients remain invariant in time, $\kappa_{\mathrm{w}}=0.04 \mathrm{~m}^{-1}$ and $\kappa_{\mathrm{c}}=0.048 \mathrm{~m}^{2} \mathrm{mg}^{-1}$. The total attenuation coefficient becomes $\kappa=\kappa_{\mathrm{w}}+\kappa_{\mathrm{c}} \cdot$ CHL $a$. The resulting value of $\kappa$ is comparable to the empirical relationship of Morel (1988) for a mixed layer mean chlorophyll concentration of $\approx 0.1 \mathrm{mg} \mathrm{CHL} a \mathrm{~m}^{-3}$.

The chlorophyll concentration of the model is determined from a variable CHL:N ratio multiplied by the modelled phytoplankton biomass. Cloern et al. (1995) suggested an empirically derived relationship for the conversion factor of carbon to chlorophyll based on a collection of a variety of experimental results. This CHL: C ratio depends on temperature, PAR and nutrient availability. The daily, depth-averaged chlorophyll to carbon ratio in the dimensions 
[mg CHL $\left.\mathrm{mg} \mathrm{C}^{-1}\right]$ is calculated as follows:

$$
\begin{aligned}
\text { CHL }: C= & 0.003+0.0154(\exp (0.050 T)) \\
& \times\left[\exp \left(\frac{-0.059 \operatorname{PAR}(1-\exp (-\kappa M))}{\kappa M}\right)\right] u
\end{aligned}
$$

with the temperature $T\left[{ }^{\circ} \mathrm{C}\right]$ and the nutrient availability for growth $u=N /(k+N)$. In Eq. (1) PAR is in the units [molquanta $\mathrm{m}^{-2} \mathrm{~d}^{-1}$ ], (for PAR $1.0 \mathrm{~W} \mathrm{~m}^{-2} \approx 0.4$ molquanta $^{-2} \mathrm{~d}^{-1}$ ). For a given constant molar $\mathrm{C}$ : $\mathrm{N}$ Redfield ratio of $106: 16,1 \mathrm{mg} \mathrm{C}$ is equivalent to $12.58 \times 10^{-3} \mathrm{mmol} \mathrm{N}$, and the chlorophyll to nitrogen ratio for the model counterpart in the dimensions $\left[\mathrm{mg} \mathrm{CHL} \mathrm{mmol}{ }^{-1}\right]$ becomes $r_{\mathrm{CHL}}(T, \mathrm{PAR}, M, u)=79.5(\mathrm{CHL}: \mathrm{C})$.

The astronomical formulae of Brock (1981) were used for the calculation of day-length and the noon irradiance at the top of the atmosphere. For the atmospheric transmittance of solar radiation the empirical function derived from Reed (1977) has been applied with a cloudiness of four oktas. The PAR just below the ocean surface is assumed to be $43 \%$ of the irradiance at the ocean surface. Although being a poor approximation, disregarding aggregation and also carnivorous feeding on herbivorous zooplankton, the loss terms (mortalities) were left to depend linearly on biomass for both compartments.

A Holling Type III function $G(P, g, \varepsilon)=g P^{2} /\left[(g / \varepsilon)+P^{2}\right]$, with a prey capture rate $\varepsilon$ and a maximum grazing rate $g$, represents the grazing by the herbivores. All 11 ecosystem model parameters $p_{v}(v=1, \ldots, 11)$ are listed in Table 1 . The differential equations for the ecosystem dynamics are: Dissolved inorganic nitrogen $(N)$ :

$$
\frac{\mathrm{d} N}{\mathrm{~d} t}=\left[-\mu u+\gamma \Phi_{P}\right] P+\left[(1-\beta) G+\Phi_{H}\right] \Omega H+\mathscr{F}_{N} .
$$

Phytoplankton biomass $(P)$ :

$$
\frac{\mathrm{d} P}{\mathrm{~d} t}=\left[\mu u-\Phi_{P}-\frac{m_{\mathrm{r}}+w_{\mathrm{e}}}{M}\right] P-G H .
$$

Herbivores (H):

$$
\frac{\mathrm{d} H}{\mathrm{~d} t}=\left[\beta G-\Phi_{H}-\frac{m_{\mathrm{r}}+w_{\mathrm{e}}}{M}\right] H
$$

with the entrainment velocity $w_{e}=\max (\mathrm{d} M / \mathrm{d} t, 0)$. It denotes entrainment with mass conservation when the mixed layer deepens, and a conservation of the nitrogen concentration when stratification occurs. The last term of Eq. (2) corresponds to the turbulent flux of dissolved nitrogen at the bottom of the mixed layer.

For the integration an Euler forward scheme with a timestep of $\tau=36$ min was chosen. Such a timestep is significantly shorter than the internal timescale of the resolved ecosystem dynamics. The mixed-layer depths were kept fixed for a 24-h period (40 timesteps). This is consistent with the assumptions made for a daily averaged light-limited growth rate $\mu$, which remains unchanged within 1 day of integration as well. A total period of $7 \mathrm{yr}$ was integrated, of which the first $2 \mathrm{yr}$ corresponded to an initial spin-up time. During these spin-up years the seasonal changes in mixed-layer depths are identical to those of the year 1989. 
Table 1

Model parameters for the variational optimization

\begin{tabular}{llll}
\hline$p_{v}$ & Symbol & Parameter & Unit \\
\hline$p_{1}$ & $\mu_{\mathrm{m}}$ & Maximum growth rate & $1 \mathrm{~d}^{-1}$ \\
$p_{2}$ & $\alpha$ & Slope of photosynthesis versus light intensity relation $(P-I)$ & $\mathrm{m}^{2} \mathrm{~W}^{-1} \mathrm{~d}^{-1}$ \\
$p_{3}$ & $\Phi_{P}$ & Phytoplankton loss & $1 \mathrm{~d}^{-1}$ \\
$p_{4}$ & $k$ & Half-saturation constant of $N$ uptake rate & $\mathrm{mmol} \mathrm{N} \mathrm{m}^{-3}$ \\
$p_{5}$ & $g$ & Maximum grazing rate & $1 \mathrm{~d}^{-1}$ \\
$p_{6}$ & $\varepsilon$ & Prey capture rate & $\mathrm{m}^{6} / \mathrm{mmol}^{-1}$ \\
& & Herbivore mortality & $\mathrm{N}^{-2} \mathrm{~d}^{-1}$ \\
$p_{7}$ & $\Phi_{H}$ & Assimilation efficiency of herbivores & $1 \mathrm{~d}^{-1}$ \\
$p_{8}$ & $\beta$ & Mixing rate & Dimensionless \\
$p_{9}$ & $m_{\mathrm{r}}$ & remineralization rate of herbivore losses & $\mathrm{m} \mathrm{d}^{-1}$ \\
$p_{10}$ & $\Omega$ & remineralization rate of phytoplankton losses & Dimensionless \\
$p_{11}$ & $\gamma$ & & Dimensionless \\
\hline
\end{tabular}

\subsubsection{Mixed-layer variability}

Two different data sets for the mixed-layer depths were constructed. A temperature difference of $\Delta T=0.2^{\circ} \mathrm{C}$ between surface and depth was used to define the mixed layer. CTD temperature profiles, averaged over night and day casts in the depth range of $z=1-400 \mathrm{~m}$, were obtained for each cruise. From the observed temperatures we constructed biweekly to monthly mixed layer depths $M_{\text {obs }}$; see Fig. 1.

From weekly mean temperatures of a three-dimensional model simulation with realistic daily forcing (heat flux, wind stress and sea-surface temperature SST), taken from the ECMWF reanalysis data (Oschlies and Ferry, personal communication), the mixed-layer depths $M_{\text {week }}$ were determined with the same $\Delta T=0.2^{\circ} \mathrm{C}$ criterion as applied to the observed data. Fig. 1a shows the mean-temperature distributions from the years 1989 to 1993 at the BATS location.

\subsubsection{Turbulent flux of dissolved inorganic nitrogen}

The turbulent flux of $N$ at the bottom of the mixed layer $(z=M)$ is defined as

$$
\mathscr{F}_{\mathcal{N}}=\frac{m_{\mathrm{r}}+w_{\mathrm{e}}}{M} \Delta N
$$

with $\Delta N=\left(N_{D}-N_{i}\right)$, the difference between the dissolved nitrogen concentrations of the mixed layer $N_{i}$ and of the layer below $N_{D}$. The strength of the nitrate flux into the mixed layer is determined by the rate multiplied by the concentration difference.

Many studies have shown that the parameterizations for the deep dissolved nitrogen concentrations $N_{D}$ (e.g. Steele and Henderson, 1992; Fasham, 1995; Hurtt and Armstrong, 1996; Spitz et al., 1998) strongly affect the model results. A constant concentration of $N_{D}$, down to a defined depth and a constant gradient below that depth, has been assumed by Fasham (1995) following Steele and Henderson (1992). Hurtt and Armstrong (1996) preferred a deep concentration that resulted from 

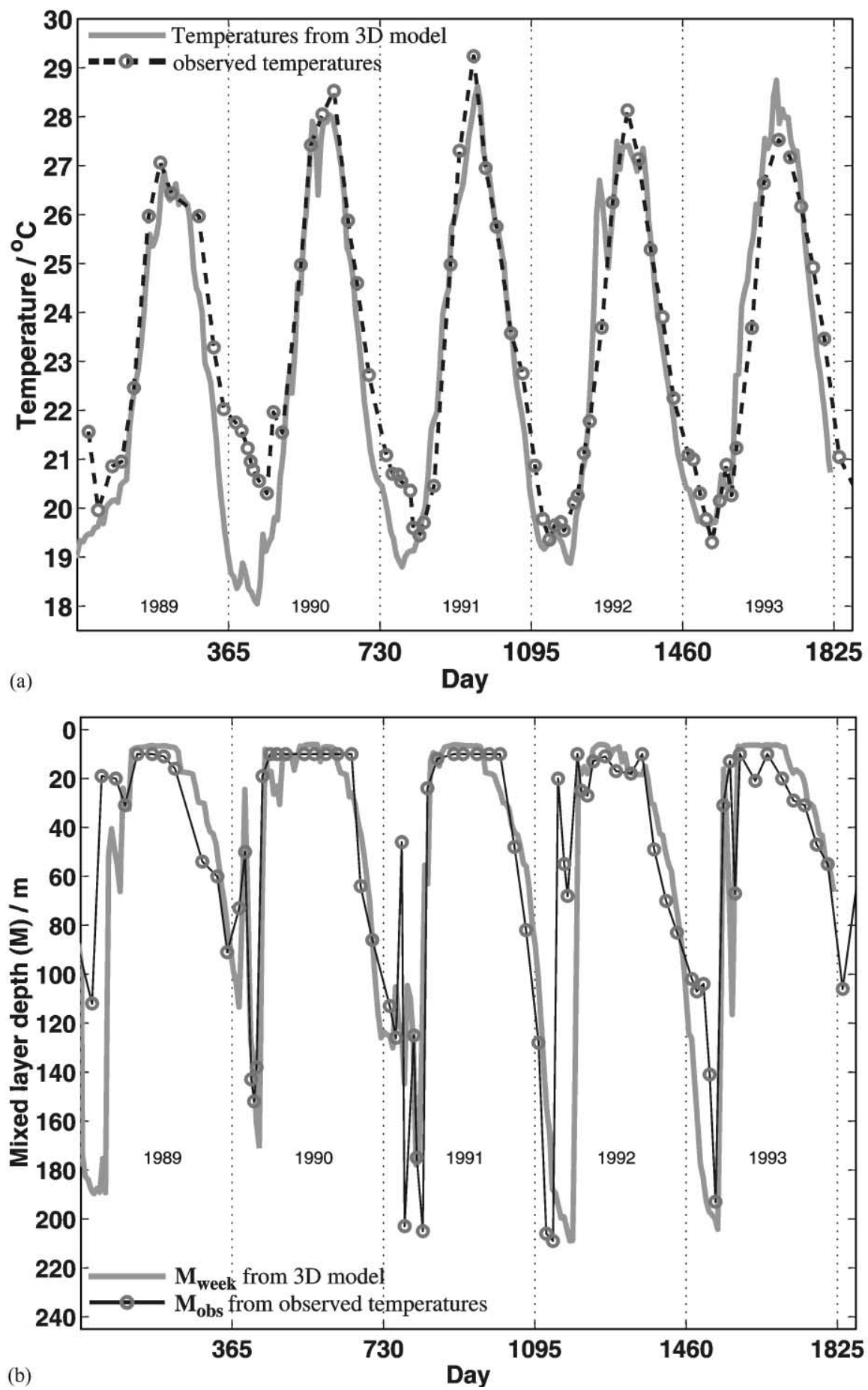

Fig. 1. Temperatures and mixed-layer depths at the Bermuda time-series station in the North Atlantic. (a) Weekly mean temperatures of the upper ocean layer of the general circulation model of the North Atlantic, under realistic forcing taken from the ECMWF reanalysis (Oschlies and Ferry, personal communication) and the observed temperatures from the BATS averaged CTD profiles (biweekly monthly measurements). (b) The resulting mixed-layer depths $M_{\text {obs }}$ and $M_{\text {week }}$ when a $0.2^{\circ} \mathrm{C}$ temperature criterion is applied. 


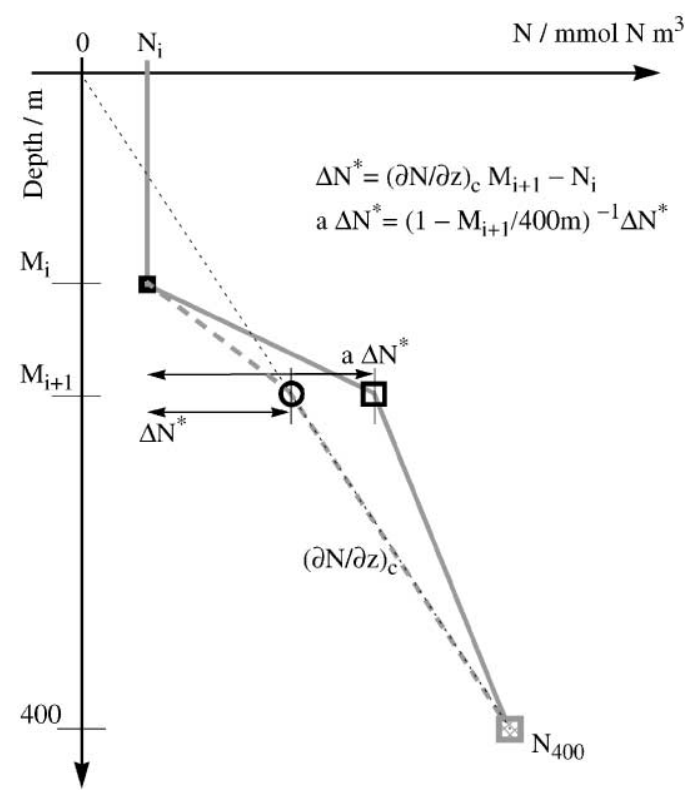

Fig. 2. Sketch to illustrate the effect of the parameterization with increased deep nutrient $N_{D}$ availability. $N_{i}$ is the modelled concentration at timestep $i$ at depth $M_{i}$. To calculate $N_{i+1}$ the turbulent flux of $N$ needs to be determined when the mixed layer deepens from $M_{i}$ to $M_{i+1}$. The gray dashed line represents the background, assuming a constant vertical gradient, $N_{\mathrm{D}}^{*}=(\partial N / \partial z)_{c} M_{i+1}=0.0125 \mathrm{mmol} \mathrm{N}^{-4} M_{i+1}$. The gray solid line illustrates the associated vertical profile for the modified parameterization with $\Delta N=a\left(N_{\vec{D}}^{*}-N_{i}\right)$; see Eqs. (5)-(7) for details.

a constant vertical $\mathrm{NO}_{2}+\mathrm{NO}_{3}$ gradient multiplied with the mixed-layer depth. Their constant gradient was determined from BATS observations within the upper $500 \mathrm{~m}$, assuming a permanent $\mathrm{NO}_{2}+\mathrm{NO}_{3}$ concentration of zero at the surface.

Applying Hurtt and Armstrongs approach, we discovered that a high mixing rate $m_{\mathrm{r}}$ was necessary to fit the observed winter/spring concentrations of $N$ within the mixed layer. As a consequence, the turbulent fluxes during the summer periods were increased as well, because $m_{\mathrm{r}}$ is considered to be invariant in time. To avoid such model behaviour a different deep nutrient parameterization was formulated. It should increase the turbulent nitrogen flux for deep mixing events. First, we define

$$
\Delta N^{*}=\left[\left(\frac{\partial N}{\partial z}\right)_{c} M-N_{i}\right]=\left[0.0125 \mathrm{mmol} \mathrm{N} \mathrm{m}^{-4} M-N_{i}\right]
$$

similar to Hurtt and Armstrong (1996), with c subscribing the constant gradient. In order to increase the turbulent flux during winter mixing, the nitrogen difference $\Delta N^{*}$ is modified by

$$
\Delta N=a \Delta N^{*}=\left(1-\frac{M}{400 m}\right)^{-1} \Delta N^{*}
$$


In winter the mixed layer deepens down to approximately $M \approx 200 \mathrm{~m}$; Fig. 1 . Hence, the turbulent flux is maximal increased by a factor of about 2 in winter. But during the summer periods, when the mixed layer is very shallow and the modelled concentrations $N_{i}$ are close to zero, $\Delta N$ approaches to $\Delta N^{*}$; see Fig. 2 .

\subsection{Optimization}

\subsubsection{The cost function}

Let $\mathbf{z}_{v}^{\text {obs }}$ denote a vector of observations at a time $t_{j}$ with the components of nitrite + nitrate, chlorophyll and ${ }^{14} \mathrm{C}$-primary production measured at BATS. At a discrete integration step $i$ the ecosystem model, which depends on the 11 biological parameters $p_{v}$, predicts the state vector $\mathbf{y}_{i}=\left(N_{i}, P_{i}, H_{i}\right)$. Not every state variable of the model can be directly compared with observational data. For example, a function for the conversion of nitrogen-based phytoplankton biomass to chlorophyll concentrations is needed. Thus, a function $f(\mathbf{y})$ transforms the state variable $\mathbf{y}$ to a model counterpart to the observations. For the optimization we introduce a cost function, which is defined as

$$
\begin{aligned}
\mathrm{J} & =J^{\mathrm{obs}}+J^{\mathrm{prior}}=\left(J^{N}+J^{\mathrm{CHL}}+J^{\mathscr{P P}}\right)+J^{\text {prior }} \\
& =\frac{1}{2} \sum_{k=1}^{3} \sum_{j=1}^{\mathcal{N}_{k}} \frac{1}{\mathscr{N}_{k} \sigma_{k j}^{2}}\left(f_{k}-z_{k}^{\mathrm{obs}}\right)_{j}^{2}+J^{\text {prior }} .
\end{aligned}
$$

The index $k$ denotes the different data types, while $j$ accounts for each individual observation, with $\mathscr{N}_{k}$, indicating the number of each type. We assume a Gaussian error distribution for the observations $z_{k j}^{\mathrm{obs}}$ and prescribe their corresponding root mean square (rms) standard deviations $\sigma_{k j}^{\text {obs }}$. Minimizing $J$, a parameter solution space is determined that is most likely to produce a best model output when compared with observations. The data-assimilation covers a period of 5 years. Temporal correlations of the data are not known, and we therefore simply scale our observational least-squares terms in Eq. (8) by their total numbers $\mathscr{N}_{k}$ combined with weights given by the inverse variances of observations.

The second term $J^{\text {prior }}$ in Eq. (8) accounts for the a priori parameter values and their estimated standard deviations $p_{v}^{\text {prior }} \pm \sigma_{p_{v}}$. This additional term avoids final parameter estimates far beyond a biologically credible range.

The standard form

$$
J^{\text {prior }}=\frac{1}{2} \sum_{v=1}^{11} \frac{1}{\sigma_{v}^{2}}\left(p_{v}^{\text {est }}-p_{v}^{\text {prior }}\right)^{2}
$$

contains a priori information considering the initial guess $p_{v}^{\text {prior }}$ to be an estimate with given variance $\sigma_{v}^{2}$, as used in optimizations by Matear (1995) and Gunson et al. (1999). This standard form assumes a Gaussian error distribution and induces a strong constraint on the estimated parameter values. Due to model errors and large uncertainties on initial parameter values, such a probability distribution is not always a good assumption. 
An alternative type of constraint is applied in this study. It does not penalize parameter estimates within a parameter range with upper and lower limits, $p_{v}^{\mathrm{u}}$ and $p_{v}^{1}$, respectively, and is of the form

$$
J^{\text {prior }}=\frac{1}{8} \sum_{v=1}^{11}\left[\frac{1}{\left(\sigma_{v}^{1}\right)^{2}}\left(\left|p_{v}^{\text {est }}-p_{v}^{1}\right|-\left(p_{v}^{\text {est }}-p_{v}^{1}\right)\right)^{2}+\frac{1}{\left(\sigma_{v}^{\mathrm{u}}\right)^{2}}\left(\left|p_{v}^{\text {est }}-p_{v}^{\mathrm{u}}\right|+\left(p_{v}^{\text {est }}-p_{v}^{\mathrm{u}}\right)\right)^{2}\right] .
$$

This means that the parameter estimates within these limits are only constrained by the observational cost function term, $J^{\text {obs }}>0$, while $J^{\text {prior }}=0$. If the optimization procedure leads to values outside the limits, Eq. (10) becomes $J^{\text {prior }}>0$. Note that, with equal upper and lower variances $\left(\sigma_{v}^{1}\right)^{2}=\left(\sigma_{v}^{\mathrm{u}}\right)^{2}=\sigma_{v}^{2}$ and when the lower and upper boundary values are chosen to be identical $p_{v}^{1}=p_{v}^{\mathrm{u}}=p_{v}^{\text {prior }}$, then Eq. (10) reduces to Eq. (9). In this study the standard deviations at the limits were assumed to be $100 \%$ of their values (Gunson et al., 1999), computing the variances $\left(\sigma_{v}^{1}\right)^{2}=\left(p_{v}^{1}\right)^{2},\left(\sigma_{v}^{\mathrm{u}}\right)^{2}=\left(p_{v}^{\mathrm{u}}\right)^{2}$.

\subsubsection{Observations}

All data were taken from the Bermuda Atlantic Time-series Study (BATS) as a part of the US Joint Global Ocean Flux Study (Michaels and Knap, 1996), and were provided by the Bermuda Biological Station for Research (BBSR). Four types of biweekly and monthly data (temperature, nitrate + nitrite, chlorophyll $a$, and ${ }^{14} \mathrm{C}$-production) have been accessed. The observations covered a time-period from January 1989 to December 1993. After a linear interpolation onto a 1-m vertical grid, the mean observed values within the mixed layer were calculated for all four types of observations. Two data sets were generated, referring to different mixed-layer depths $M_{\text {week }}$ and $M_{\text {obs }}$.

A total of $\mathscr{N}_{n}=76$ nitrate profile measurements were combined with those of nitrite. The $N$ component of the cost function is

$$
J^{N}=\frac{1}{2 \mathscr{N}_{n}} \sum_{j=1}^{\mathcal{N}_{n}} \frac{1}{\sigma_{\text {din }}^{2}}\left(N-\left(\mathrm{NO}_{3}+\mathrm{NO}_{2}\right)^{\mathrm{obs}}\right)_{j}^{2}
$$

The variance $\sigma_{\mathrm{din}}^{2}$ was calculated from the variances $\sigma_{\mathrm{din}}^{2}=\sigma_{\mathrm{NO}_{2}}^{2}+\sigma_{\mathrm{NO}_{3}}^{2}=\left(4 \times 10^{-4}+6.4 \times 10^{-3}\right)$ $\mu \mathrm{mol}^{2} 1^{-2}=6.8 \times 10^{-3} \mu \mathrm{mol}^{2} 1^{-2}$ of both measurement methods (JGOFS, 1996; Grasshoff et al., 1999). Observed ammonium concentrations fall into the range of nitrate and nitrite errors and were neglected.

For adding chlorophyll data to the cost function a counterpart of simulated chlorophyll is computed from phytoplankton nitrogen; see Eq. (1). The chlorophyll term then becomes

$$
J^{\mathrm{CHL}}=\frac{1}{2 \mathscr{N}_{\mathrm{c}}} \sum_{j=1}^{\mathscr{N}_{\mathrm{c}}} \frac{1}{\left(\sigma_{j}^{\mathrm{CHL}}\right)^{2}}\left(r_{\mathrm{CHL}}(T, \mathrm{PAR}, M, u) P-\mathrm{CHL}^{\mathrm{obs}}\right)_{j}^{2}
$$

for $\mathscr{N}_{\mathrm{c}}=76$ observations. The variances in chlorophyll concentrations should implicitly account for heterogeneous spatial distributions. Errors due to this kind of patchiness are mostly described as relative errors and are here taken into account by $\sigma_{j}^{\mathrm{r}}=0.15 \mathrm{CHL}_{j}^{\mathrm{obs}}$. But these proportional errors lead to apparent discrepancies in the residuals between observations and model counterparts, as shown by Prunet et al. (1996). To avoid too small errors for low chlorophyll measurements we added an absolute error of $\sigma_{\mathrm{a}}=0.01 \mathrm{mg} \mathrm{CHL}$, derived from replicate analysis of Herbland et al. (1985). Hence, the variances were $\left(\sigma_{j}^{\mathrm{CHL}}\right)^{2}=\left(\sigma_{\mathrm{a}}\right)^{2}+\left(\sigma_{j}^{\mathrm{r}}\right)^{2}$. 
${ }^{14} \mathrm{C}$-production data (Michaels and Knap, 1996) were used. In order to approximate net primary production, the dark measurements were subtracted from the observations with light. A total of $\mathscr{N}_{p}=66$ profiles entered the optimization.

$$
J^{\mathscr{P P}}=\frac{1}{2 \mathscr{N}_{p}} \sum_{j=1}^{\mathcal{N}_{p}} \frac{1}{\left(\sigma_{j}^{\mathscr{P P}}\right)^{2}}\left(R \mu u P-\mathscr{P} \mathscr{P}^{\mathrm{obs}}\right)_{j}^{2}
$$

The ratio $R$ transforms the modelled photosynthetically fixed nitrogen to primary produced carbon by $R=79.52 \mathrm{mg} \mathrm{Cmmol} \mathrm{N}{ }^{-1}$. Following Richardson (1991), we prescribed an absolute error of $\sigma_{\mathrm{a}}=0.46 \mathrm{mg} \mathrm{C} \mathrm{m}^{-3} \mathrm{~d}^{-1}$, which resulted from $12 \%$ of the total mean mixed-layer production $\overline{\mathscr{P} P}=3.83 \mathrm{mg} \mathrm{C} \mathrm{m}^{-3} \mathrm{~d}^{-1}$. The relative error contribution was very conservatively considered as $\sigma_{j}^{\mathrm{r}}=40 \%$ of the observed value (JGOFS, 1996; Richardson, 1991).

\subsubsection{The adjoint method}

Here, we utilized the variational adjoint method to find the optimal parameter set of an ecosystem model fitted to measurements. The adjoint method provides the gradients of the cost function $J$ with respect to the parameters $p_{v}$. The relatively simple structure of the model allows the derivation of an adjoint model directly. The adjoint equations were calculated from the discrete prognostics of the forward model (e.g. Thacker, 1987; Smedstad and O'Brian, 1991) and are listed in Appendix A.

For the minimization a routine, based on the so-called variable metric method of Fletcher and Powell (1963), was utilized (see Press et al., 1992). The algorithm, which was applied here, was tested extensively in meteorology and physics (Wagner and Lovelace, 1971; Jung et al., 1998). An approximated error matrix, the square root of the inverse diagonal elements of the Hessian $H_{v v}^{-1}$, also laid down the convergence criterium for the step size vector $s_{v}$. The algorithm stopped as soon as $s_{v} \leqslant 0.1 . \sqrt{H_{v v}^{-1}}$ was satisfied for all $v$ parameters.

\section{Experiments and model configurations}

Five experiments were designed to investigate the most relevant misfits between the simple ecosystem model and the mixed-layer data. In order to explore the cost function's structure hundreds of individual optimizations were performed, using a wide range of parameter guesses. All experiments started from the same set of 600 a priori parameter values (initial guesses). The rationale behind the number of exactly 600 was simply computational time. The initial guesses of the parameter values were randomly generated within a parameter space bounded by $p_{v}^{1}$ and $p_{v}^{u}$; see Eq. (10). The bounds were chosen as extreme values, known from model sensitivity studies (e.g. Fasham, 1995).

Four experiments (A1, A2, A3 and B) were conducted with real observational data from BATS, including interannual variations. In experiments $\mathrm{A} 1$ and $\mathrm{A} 2$ we compared optimization results due to changes in mixed-layer variability. For experiment A3 the parameterization of the deep nutrient $N_{D}$ was substituted by observed nitrate + nitrite concentrations. Finally, we added zooplankton observations (experiment B) to the assimilation scheme and hoped to find optimal model results with increased nutrient recycling during summer together with a low biomass of herbivores. 
Table 2

List of the performed experiments ${ }^{\mathrm{a}}$

Model configuration

\begin{tabular}{|c|c|c|c|c|c|}
\hline Experiments & $\mathrm{TE}$ & A1 & $\mathrm{A} 2$ & A3 & $\mathrm{B}$ \\
\hline Mixed-layer depths & $M_{\text {week }}$ & $M_{\mathrm{obs}}$ & $M_{\text {week }}$ & $M_{\mathrm{obs}}$ & $M_{\text {week }}$ \\
\hline$N_{D}$ availability & Parameterized & Parameterized & Parameterized & Prescribed & Parameterized \\
\hline Zooplankton observations & No & No & No & No & Yes \\
\hline
\end{tabular}

${ }^{a}$ The twin experiment TE was performed to investigate the parameter solution space, to define a practical criterion for the optimal parameter estimates and to test the robustness of the adjoint method. In experiments A1, A2 and A3 the sensitivity of different deep nutrient availabilities to variations in mixed layer depths was determined. Experiment $\mathrm{B}$ analysed the influence of additional zooplankton observations on the optimal parameter solutions and on the corresponding model results.

In addition, a twin experiment (TE) is presented to define a criterion for the analysis of the optimal parameter estimates and to disclose the robustness of the method. We start with the presentation of the twin experiment since the derived criterion was then adopted to interpret the results of the following experiments. Table 2 summarizes the different model assumptions for all experiments.

\subsection{Experiments TE and A: sensitivity to deep nutrient availability}

\subsubsection{Twin experiment TE}

Before starting with experiment TE, we already had conducted experiment A1, which was performed with real data. Actually, the best parameter solution $p_{v}^{\text {best }}$, producing the lowest cost function value of experiment A1, was taken as reference solution $p_{v}^{\text {ref }}$ for experiment TE. This procedure assured a twin experiment with reference parameter values closely related to the best parameter solutions of the assimilation experiment with real data. Otherwise, the twin experiment could have been conducted within a completely different parameter space, perhaps producing different results.

For the twin experiment a synthetic daily data set was generated. Simulating daily observations excluded possible errors due to the sampling rate and was intended to provide an ideal criterion for the analysis of the parameter solutions. Model realizations $f_{k}$ (model counterparts of $\mathscr{P} \mathscr{P}, N$ and CHL) over a period of the simulated $5 \mathrm{yr}$ were used as a basis for the synthetic data. To simulate observations $z_{k j}^{\text {obs }}$ we added Gaussian noise to the daily model realizations with the same variances as they were assumed for the observational data. The additional noise produced few negative chlorophyll concentrations. By taking always the absolute values we introduced a small bias towards lower synthetic chlorophyll concentrations.

3.1.1.1. Results TE. If we interpret the optimal fit as a weighted least-squares estimate, then all minimizations should have converged close to an expected cost function value of $J \approx \frac{3}{2}$, 


\section{Twin experiment TE}

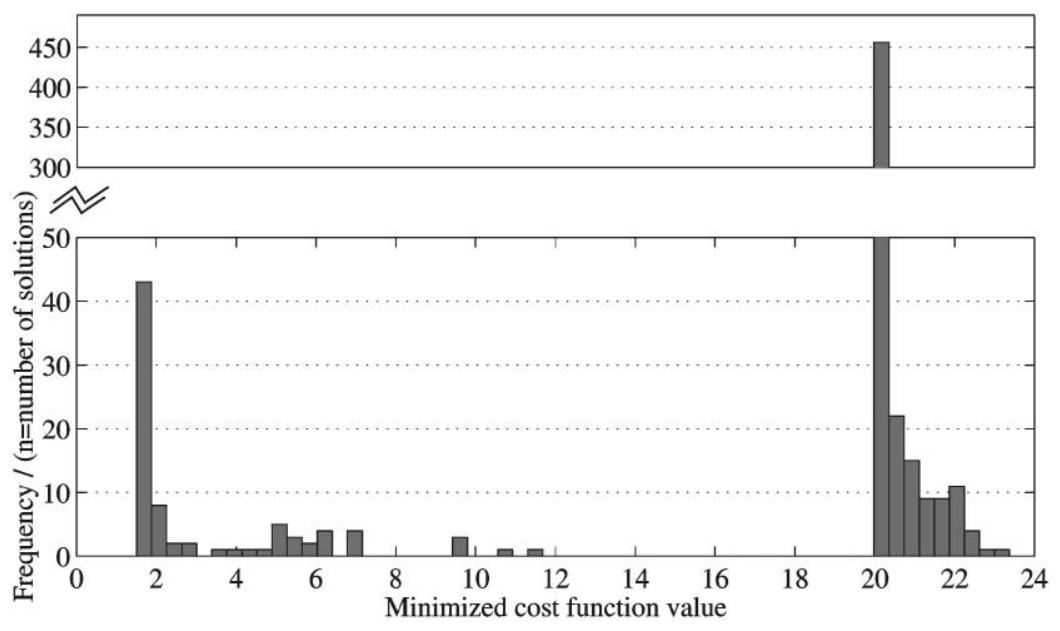

Fig. 3. Twin experiment TE. (a) The frequency distribution of the minimized cost functions for all optimizations. Two significant peaks can be determined, corresponding to a local and to the global minimum of the cost function. The gray dashed frames indicate the scales of figures (b) and (c) with the peaks separated. (b) Frequency distribution close to the value of expectation $J=1.5$ (global minimum). The width of the bars indicate the length of the intervals. The number of solutions falling into each interval was counted. (c) Frequency distribution close to the local minimum $J \approx 20$. Note that the scales are different to figure (b).

corresponding to an error

$$
\varepsilon_{k}^{2}=\sum_{j=1}^{N_{k}} \frac{1}{\mathscr{N}_{k} \sigma_{k j}^{2}}\left(f_{k}-z_{k}^{\mathrm{obs}}\right)_{j}^{2} \approx 1
$$

for each observational term $k$. This would mean that on average each misfit falls within the range of the given observational error variance. Further, if all parameter solutions were normally distributed, the error $\varepsilon^{2}$ should follow a Chi-squared distribution, which could then be used to determine the confidence limits for the parameter estimates (unbiased estimation). However, the distribution, derived from the individual minimizations, differed significantly from that of a Chi-squared; Fig. 3. Actually a total of $n=456$ of the 600 optimizations converged to cost function values within the range $20.1<J<20.5$. These parameter estimates, which correspond to a local minimum of the cost function, described a model with no phytoplankton and zooplankton biomass (dead solution with $P=H=0$ ).

To determine those parameter estimates corresponding to the global minimum solution, we took all parameter values that produced a final cost function close to the expected value $J \approx \frac{3}{2}$. A number of $n=43$ solutions ended within $1.5<J \leqslant 1.88$, according to an error of no more than $25 \%$ with respect to the lowest cost function value achieved $\left(J_{\text {best }}\right)$. A pragmatic criterion was defined: only those solutions within an "acceptable region" $J \leqslant 1.25 J_{\text {best }}$ were considered; Fig. 4.

With the three integrated terms of nutrients, chlorophyll and production, the best cost function value achieved was $J_{\text {best }}=J^{N}+J^{\mathrm{CHL}}+J^{\mathscr{P S}}+J^{\text {prior }}=0.359+0.675+0.473+0.000=1.507$. 


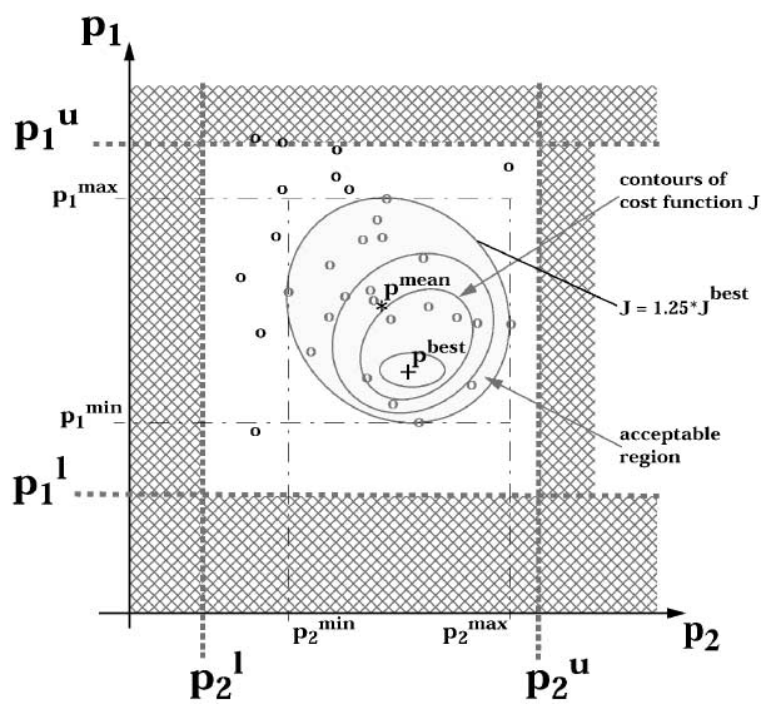

Fig. 4. A sketch of a two- dimensional parameter space. The values $p_{1}^{1}, p_{2}^{1}$ and $p_{1}^{\mathrm{u}}, p_{2}^{\mathrm{u}}$ describe the lower and upper penalty limits at which the parameter penalty term becomes $J^{\text {prior }}>0$ ("hatched region"). All final parameter estimates (solution space, "gray marked region") are indicated by the small circles "o". The best parameter values $\left(p_{1}^{\text {best }}, p_{2}^{\text {best }}\right)$ are those estimates which produced the lowest cost function value $J^{\text {best }}$. The acceptable region is defined such that all parameter solutions with a cost function value $J \leqslant 1.25 J^{\text {best }}$ were included. From those solutions which fall into the defined acceptable region we calculated the mean parameters $\left(p_{1}^{\text {mean }}, p_{2}^{\text {mean }}\right)$. In addition, the extreme values $\left(p_{1}^{\min }, p_{2}^{\min }\right)$ and $\left(p_{1}^{\max }, p_{2}^{\max }\right)$ describe the extensions of the prescribed acceptable region $\Delta J \leqslant 1.25 J^{\text {best }}$.

The errors in chlorophyll can be interpreted as a shift of the model solutions towards the lower pseudo-observational values; Fig. 5. This problem may arise with error distributions that are proportional to the observed value, as stated by Prunet et al. (1996), when lower values are favoured due to higher weights.

Table 3 lists the parameter solutions $p_{v}^{\text {best }}$, corresponding to the best cost function value together with the averaged parameter values $p_{v}^{\text {mean }}$ of the $n=43$ solutions that fulfilled the criterion $J \leqslant 1.25 J_{\text {best }}$. The upper and lower limits of the acceptable region are listed as $p_{v}^{\min }$ and $p_{v}^{\max }$, respectively.

To interpret the distinguishable features between the local minimum and the global minimum solution we focused on the maximum growth rate $\mu_{\mathrm{m}}$ and the zooplankton assimilation efficiency $\beta$. For the local solution we considered $n=208$ final estimates with a cost function within the more precise limits $20.15<J<20.2$. While the local solution suggested low estimates of $\mu_{\mathrm{m}}$, the assimilation efficiency $\beta$ became redundant. But these two parameters were much better confined within the acceptable region of the global minimum. Fig. 6a illustrates these differences within the two-dimensional parameter space. Fig. $6 \mathrm{~b}$ shows two cost functions for $\beta=1.0$ and 0.5 , which result from one-dimensional variations (in parameter space) of the maximum growth rate $\mu_{\mathrm{m}}$, keeping the other parameters fixed at their reference values. The figure represents the local as well as the global minimum of the cost function. 

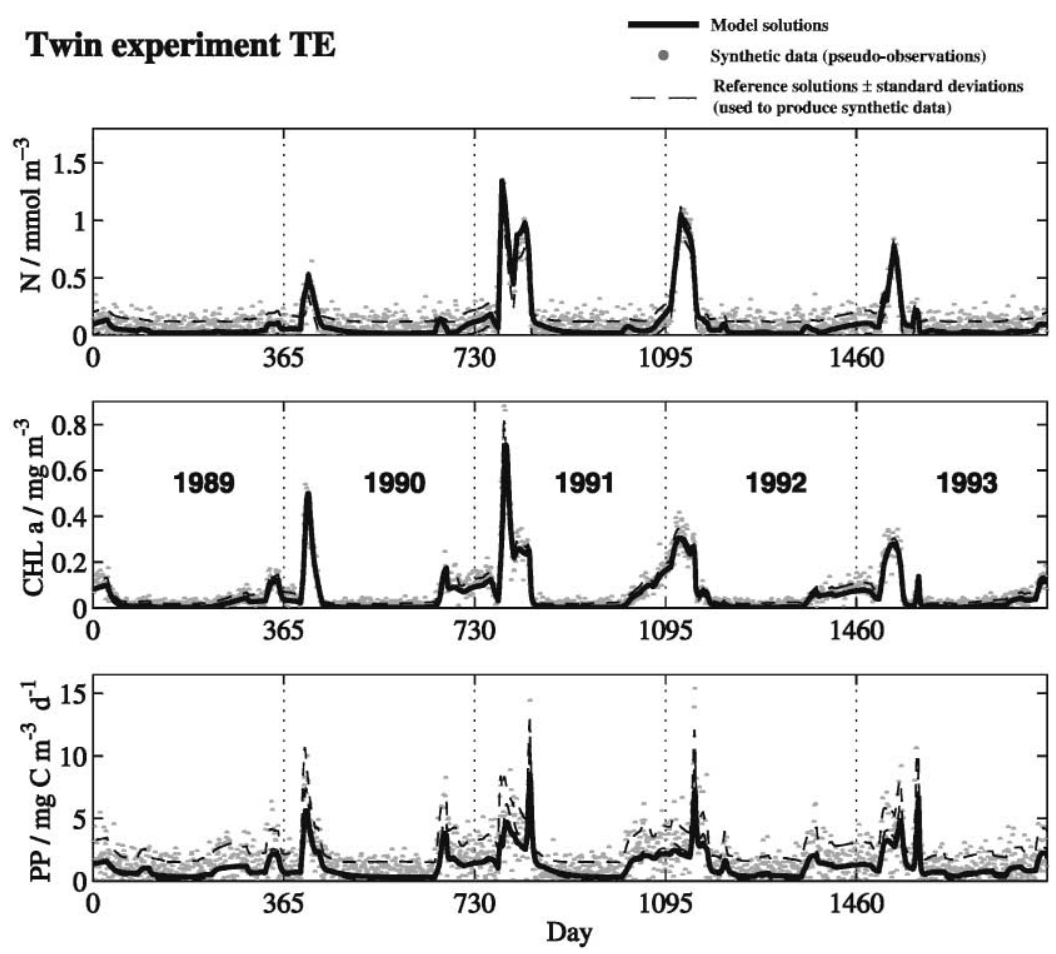

Fig. 5. Twin experiment TE. Synthetic observations (gray dots) of dissolved inorganic nitrogen $\left(N,\left[\mathrm{mmol} \mathrm{m}^{-3}\right]\right)$, chlorophyll $a$ (CHL $\left.a,\left[\mathrm{mg} \mathrm{m}^{-3}\right]\right)$ and primary production $\left[P P,\left[\mathrm{mg} \mathrm{Cm}^{-3} \mathrm{~d}^{-1}\right]\right.$ ) together with the optimal model solutions (bold black lines). For the twin experiment the biweekly monthly variations of the mixed layer depths $M_{\mathrm{obs}}$ were utilized. The dashed lines indicate the reference solutions \pm the assumed standard deviations.

\subsubsection{Experiments $A 1$ and A2: Mixed-layer variability and parameterized deep nitrogen concentrations}

In Section 3.1.1 a criterion for an acceptable a posteriori region in the parameter space was defined (hereafter referred to as $\Delta J$-criterion). The inclusion of real observational data is expected to make the error distribution worse than the one determined in the twin experiment, because of the decreased sampling rates. Since the strict criterion will not be improved when real data are used, we adopt it from experiment TE for the following assimilation experiments to obtain the optimal parameter solutions.

The influence of different mixed-layer variabilities on the optimal parameter estimates and on the resulting model dynamics was determined. Two kinds of variabilities of the mixed-layer depths ( $M_{\mathrm{obs}}$ in $\mathrm{Al}$ and $M_{\text {week }}$ in A2) were applied together with the corresponding observations. For each experiment a total of 600 individual optimizations were conducted, starting from the same set of initial guesses.

3.1.2.1. Results of experiments $A 1$ and $A 2$. The initial cost function values ranged from $J \approx 30$ to maximal 500. During optimization, the cost function values decreased by about two orders of 
Table 3

Twin experiment $\mathrm{TE}^{\mathrm{a}}$

\begin{tabular}{|c|c|c|c|c|c|c|c|}
\hline \multicolumn{3}{|c|}{ Parameters } & \multirow{2}{*}{$\begin{array}{l}\text { Penalty limits } \\
p_{v}^{1} / p_{v}^{\mathrm{u}}\end{array}$} & \multirow{2}{*}{$\begin{array}{l}\text { Reference values } \\
p_{v}^{\text {ref }}\end{array}$} & \multirow{2}{*}{$\frac{p_{v}^{\text {best }}}{\text { Global }}$} & \multirow{2}{*}{$\frac{p_{v}^{\text {mean }}}{\text { Global }}$} & \multirow{2}{*}{$\frac{p_{v}^{\min } / p_{v}^{\max }}{\text { Global }}$} \\
\hline$v$ & Symbol $p_{v}$ & Unit & & & & & \\
\hline 1 & $\mu_{\mathrm{m}}$ & $1 \mathrm{~d}^{-1}$ & $0.100 / 3.000$ & 2.614 & 2.023 & 1.928 & $1.486 / 2.654$ \\
\hline 2 & $\alpha$ & $\mathrm{m}^{2} \mathrm{~W}^{-1} \mathrm{~d}^{-1}$ & $0.025 / 0.700$ & 0.483 & 0.235 & 0.370 & $0.188 / 0.671$ \\
\hline 3 & $\Phi_{P}$ & $1 \mathrm{~d}^{-1}$ & $0.010 / 0.100$ & 0.020 & 0.011 & 0.030 & $0.010 / 0.091$ \\
\hline 4 & $k$ & $\operatorname{mmolN~} \mathrm{m}^{-3}$ & $0.100 / 0.700$ & 0.276 & 0.192 & 0.300 & $0.142 / 0.465$ \\
\hline 5 & $g$ & $1 / \mathrm{d}^{-1}$ & $0.100 / 1.000$ & 1.000 & 0.995 & 0.927 & $0.541 / 1.114$ \\
\hline 6 & $\varepsilon$ & $\begin{array}{l}\mathrm{m}^{6} \mathrm{mmol}^{-1} \\
\mathrm{~N}^{-2} \mathrm{~d}^{-1}\end{array}$ & $0.100 / 3.000$ & 2.874 & 2.940 & 2.745 & $1.963 / 3.221$ \\
\hline 7 & $\Phi_{\mathrm{h}}$ & $1 \mathrm{~d}^{-1}$ & $0.010 / 0.100$ & 0.010 & 0.012 & 0.016 & $0.009 / 0.048$ \\
\hline 8 & $\beta$ & 1 & $0.100 / 1.000$ & 1.000 & 1.014 & 1.025 & $0.923 / 1.098$ \\
\hline 9 & $m_{\mathrm{r}}$ & $\mathrm{m} \mathrm{d}^{-1}$ & $0.010 / 3.000$ & 0.700 & 0.379 & 0.245 & $0.013 / 0.457$ \\
\hline 10 & $\Omega$ & 1 & $0.100 / 1.000$ & 0.578 & 0.486 & 0.602 & $0.110 / 1.151$ \\
\hline 11 & $\gamma$ & 1 & $0.100 / 1.000$ & 0.961 & 0.274 & 0.537 & $0.129 / 1.011$ \\
\hline
\end{tabular}

${ }^{\text {a }}$ The best estimate $p_{v}^{\text {mean }}$ is a solution which corresponds to the lowest cost function value $J_{\text {best }}$. Mean values $p_{v}^{\text {mean }}$ were calculated from a number of $n=43$ parameter solutions that fall into the prescribed acceptable region $\Delta J=1.25 J_{\text {best }}$, with $J_{\text {best }}=1.507$. The lowest $p_{v}^{\min }$ and the highest parameter values $p_{v}^{\max }$ describe the acceptable parameter space for $p_{v}^{\text {mean }}$.

magnitude. The best fit to observations was achieved in experiment A2 with a weekly varying mixed-layer depth variability $M_{\text {week }}$. The cost function value had converged to a value of $J_{\text {best }}=J^{N}+J^{\mathrm{CHL}}+J^{\mathscr{P P P}}+J^{\text {prior }}=0.919+3.431+0.868+0.003=5.221$, with the greatest misfit in chlorophyll. For the calculation of $p_{v}^{\text {mean }}$ we could account for $n=54$ solutions $(9 \%)$ that ended in the acceptable region $\Delta J=1.25 J_{\text {best }}$. In experiment $\mathrm{A} 1$ (with $M_{\text {obs }}$ ) the best final cost function value was $J_{\text {best }}=J^{N}+J^{\mathrm{CHL}}+J^{\mathscr{P P}}+J^{\text {prior }}=1.298+3.617+0.883+0.002=5.800$, with the greatest misfit in chlorophyll as well. The number of considered solutions increased to $n=76$, yielding $13 \%$ of the total number of optimizations.

As listed in Table 4, the mean parameter values did not show significant differences between experiments A1 and A2. For both experiments the growth parameters resulted in high values close to the upper bounds $p_{v}^{\mathrm{u}}$. The phytoplankton loss parameter could not be sufficiently well constrained by the data, and the highest and lowest estimates within the acceptable region fell together with the upper and lower bounds of the initial guesses. The optimal estimates for the halfsaturation constant $k$ of the nitrogen uptake were similar for both experiments. Small values for $k$ prevailed and no estimate exceeded $0.391 \mathrm{mmol} \mathrm{N} \mathrm{m}^{-3}$. The results for the three control parameters of the zooplankton, the maximum grazing rate $g$, prey capture rate $\varepsilon$ and the assimilation efficiency $\beta$ were remarkable. In order to maintain high productivity of the phytoplankton together with low chlorophyll concentrations, as required to fit the ${ }^{14} \mathrm{C}$-production and chlorophyll data, these three parameters reached high values without getting too much penalty from the additional cost function term $J^{\text {prior }}$. Somewhat unexpectedly, the optimal mixing rate, $m_{\mathrm{r}}$, did not vary much between experiments A1 and A2, even though the development of the mixed 


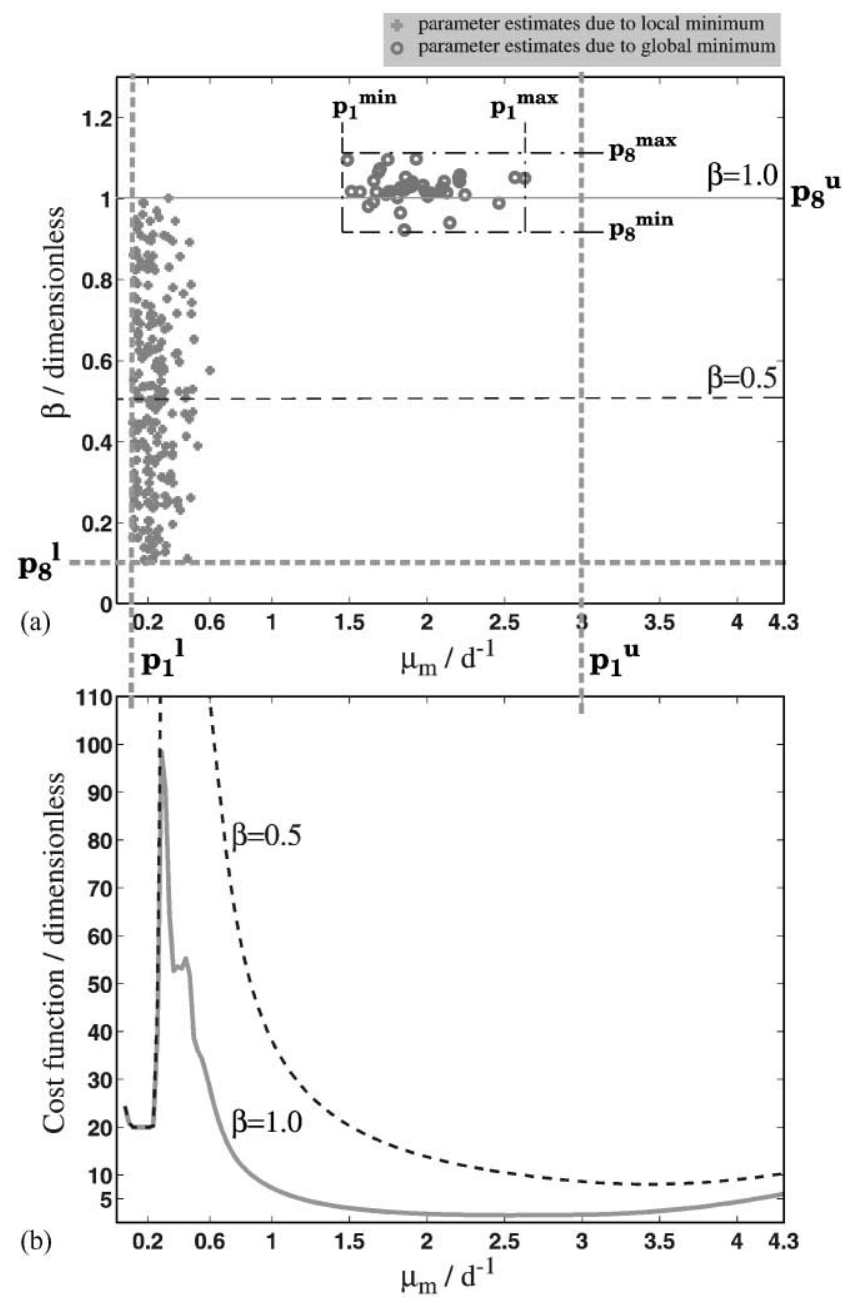

Fig. 6. (a) Projection on the two-dimensional parameter solution space, with the zooplankton assimilation efficiency $\beta$ and the phytoplankton maximum growth rate $\mu_{\mathrm{m}}$. As in Fig. 3, the upper and lower penalty limits $\left(p_{1}^{\mathrm{u}}, p_{2}^{\mathrm{u}}\right)$ and $\left(p_{1}^{1}, p_{2}^{1}\right)$ are added. (b) One-dimensional variation of the maximum growth rate $\mu_{\mathrm{m}}$ while the other parameters remained to their fixed reference values; see Table 3. The gray line indicates the cost function values for a fixed $\beta=1.0$, which corresponds to the reference value. The black dashed line shows the cost function when the assimilation efficiency was kept at $\beta=0.5$.

layer and hence the entrainment rates were different. Fig. 7 shows the observations and the model results for the $p_{v}^{\text {mean }}$ and $p_{v}^{\text {best }}$ solutions of A1. The two model solutions are very similar, justifying the pragmatic $\Delta J$-criterion. Hence, for experiment $\mathrm{A} 2$ only the model solutions that corresponded to the mean parameter values are shown.

For $5 \mathrm{yr}$ of integration, the modelled primary production was lower than observed. Total averaged primary production of the model resulted in $\overline{\mathscr{P} P}=43 \mathrm{gC} \mathrm{m}^{-2} \mathrm{yr}^{-1}$ for experiment A1. As we increased the variability of the mixed-layer depths in experiment A2 the mean primary 
Table 4

Experiments A1, A2 and $\mathrm{B}^{\mathrm{a}}$

\begin{tabular}{|c|c|c|c|c|c|c|c|c|c|c|}
\hline \multicolumn{3}{|c|}{ Parameters } & \multicolumn{2}{|c|}{ Penalty limits } & \multicolumn{3}{|l|}{$\mathrm{p}_{v}^{\text {mean }}$} & \multicolumn{3}{|l|}{$\mathrm{p}_{v}^{\min } / p_{v}^{\max }$} \\
\hline$v$ & Symbol $p_{v}$ & Unit & $p_{v}^{1}$ & $p_{v}^{\mathrm{u}}$ & $\mathrm{A} 1$ & $\mathrm{~A} 2$ & $\mathrm{~B}$ & A1 & $\mathrm{A} 2$ & B \\
\hline 1 & $\mu_{\mathrm{m}}$ & $1 \mathrm{~d}^{-1}$ & 0.100 & 3.000 & 2.396 & 2.980 & 2.187 & $1.847 / 3.007$ & $2.181 / 3.723$ & $0.336 / 3.007$ \\
\hline 2 & $\alpha$ & $\mathrm{m}^{2} \mathrm{~W}^{-1} \mathrm{~d}^{-1}$ & 0.025 & 0.700 & 0.384 & 0.458 & 0.432 & $0.184 / 0.660$ & $0.106 / 0.744$ & $0.173 / 0.688$ \\
\hline 3 & $\Phi_{P}$ & $1 \mathrm{~d}^{-1}$ & 0.010 & 0.100 & 0.034 & 0.041 & 0.022 & $0.010 / 0.086$ & $0.010 / 0.098$ & $0.010 / 0.031$ \\
\hline 4 & $k$ & $\operatorname{mmolN~m} \mathrm{N}^{-3}$ & 0.100 & 0.700 & 0.159 & 0.170 & 0.289 & $0.086 / 0.332$ & $0.089 / 0.391$ & $0.097 / 0.395$ \\
\hline 5 & $g$ & $1 \mathrm{~d}^{-1}$ & 0.100 & 1.000 & 1.035 & 1.031 & 1.237 & $0.590 / 1.190$ & $0.588 / 1.176$ & $0.743 / 1.459$ \\
\hline 6 & $\varepsilon$ & $\mathrm{m}^{6} \mathrm{mmolN}^{-2} \mathrm{~d}^{-1}$ & 0.100 & 3.000 & 3.031 & 3.145 & 2.947 & $1.946 / 3.326$ & $2.456 / 3.342$ & $2.403 / 3.364$ \\
\hline 7 & $\Phi_{\mathrm{h}}$ & $1 \mathrm{~d}^{-1}$ & 0.010 & 0.100 & 0.012 & 0.011 & 0.040 & $0.010 / 0.050$ & $0.009 / 0.022$ & $0.010 / 0.067$ \\
\hline 8 & $\beta$ & 1 & 0.100 & 1.000 & 1.037 & 1.025 & 0.863 & $0.810 / 1.148$ & $0.827 / 1.116$ & $0.674 / 1.066$ \\
\hline 9 & $m_{\mathrm{r}}$ & $\mathrm{m} \mathrm{d}^{-1}$ & 0.010 & 3.000 & 0.630 & 0.681 & 1.069 & $0.009 / 1.840$ & $0.012 / 1.703$ & $0.114 / 2.428$ \\
\hline 10 & $\Omega$ & 1 & 0.010 & 1.000 & 0.593 & 0.662 & 0.398 & $0.099 / 1.142$ & $0.098 / 1.100$ & $0.241 / 0.773$ \\
\hline 11 & $\gamma$ & 1 & 0.010 & 1.000 & 0.583 & 0.662 & 0.625 & $0.099 / 1.018$ & $0.122 / 1.041$ & $0.317 / 0.937$ \\
\hline
\end{tabular}

${ }^{\text {a }}$ The best estimate $p_{v}^{\text {best }}$ is a solution which corresponds to the lowest cost function value $J_{\text {best }}$. Mean values $p_{v}^{\text {mean }}$ were calculated from a number of $n$ parameter solutions that lead into a prescribed acceptable region $\Delta J=1.25 J_{\text {best }}$ : (A1) $\rightarrow n=76, J_{\text {best }}=5.800$; (A2) $\rightarrow n=54, J_{\text {best }}=5.221$; (B) $\rightarrow n=8, J_{\text {best }}=22.065$. The lowest $p_{v}^{\text {min }}$ and the highest parameter values $p_{v}^{\max }$ described the acceptable parameter space for $p_{v}^{\text {mean }}$.

production was enhanced, $\overline{\mathscr{P} \mathscr{P}}=59 \mathrm{gC} \mathrm{m}^{-2} \mathrm{yr}^{-1}$. Comparing with the chlorophyll data, we noticed that the most obvious misfit appeared during the summer periods. In both experiments the chlorophyll concentrations were underestimated $\left(<0.03 \mathrm{mg} \mathrm{CHL} \mathrm{m}^{-3}\right)$. Apparently, the modelled remineralization was insufficient and could not maintain higher production rates in summer. The uncertain estimates of the remineralization parameters caused a model result that produced annually averaged $f$-ratios of 0.74 for experiment $\mathrm{A} 1$ and 0.72 for experiment $\mathrm{A} 2$. Such high $f$-ratios are very unrealistic at BATS. Our approximated $f$-ratio from the model was calculated from the amounts of $N$ in new and regenerated form, but we could not compute the degree to which regenerated $N$ was used preferentially in primary production. Consequently, the computed $f$-ratio is likely to be overestimated. The ecosystem model of Hurtt and Armstrong (1996) predicted an average $f$-ratio within the realistic range of 0.06-0.31 as estimated by Eppley and Peterson (1979), Platt Harrison (1985) and Michaels (1995). Another remarkable feature in experiment A1 (not present in experiment A2) was the misfit of $N$ in March 1991. Because of this error in the entrained $N$, the other modelled state variables responded and induced similar errors in chlorophyll and primary production. It reflects the sensitivity of the model to the approximated mixed-layer depths and to possible effects due to advective processes.

The model solutions show moderate fits to observations, which do not significantly differ from the fits of more complex models, such as Hurtt and Armstrong (1996) and Spitz et al. (1998). However, Fig. 8 shows how these results are due to an unrealistic high abundance of zooplankton, compared to observed values (e.g. Caron et al., 1995). No constraints were formulated for the 

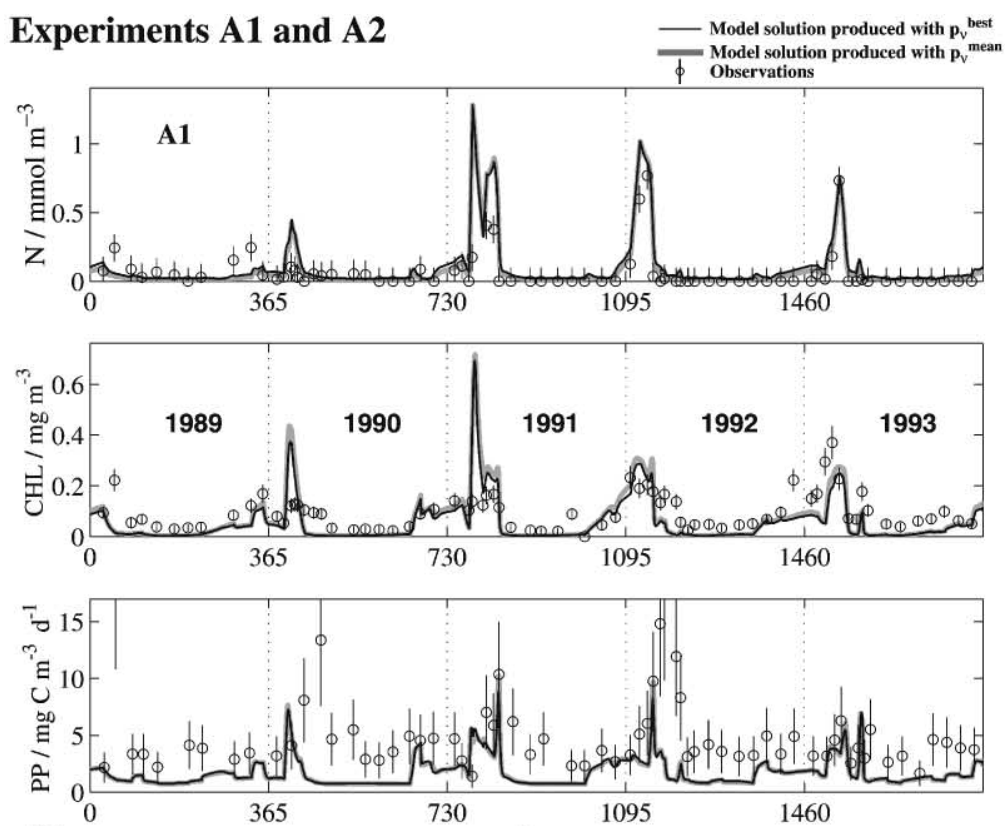

(a)

Day

$\bar{\phi}$ Observations
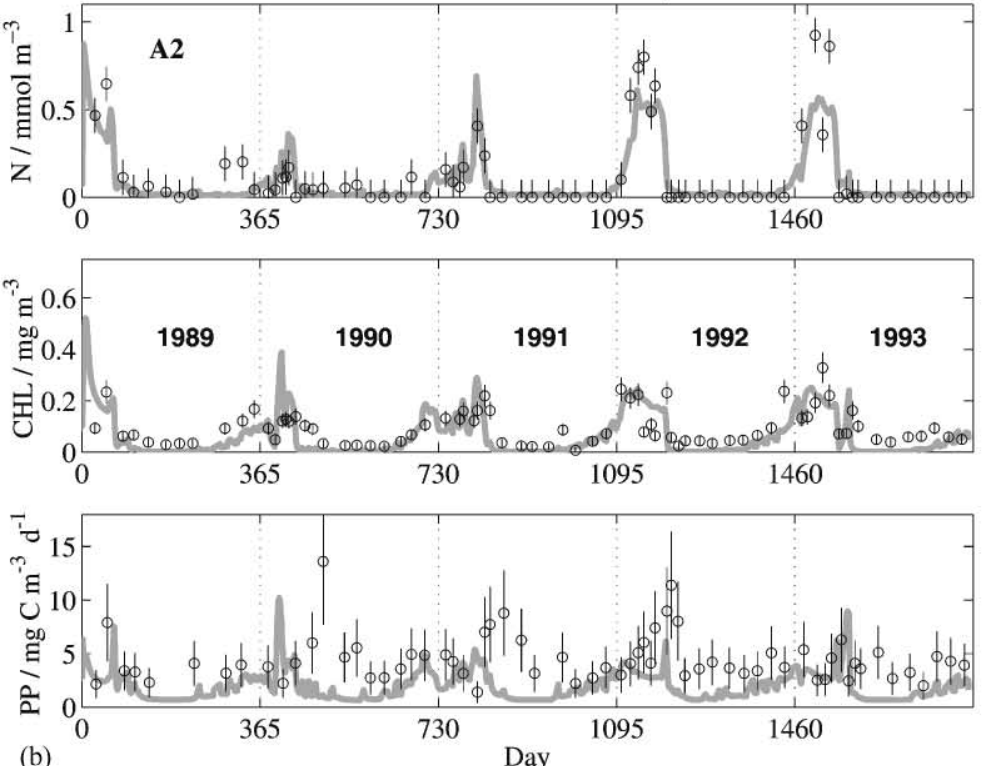

Fig. 7. Experiments $\mathrm{A} 1$ and $\mathrm{A} 2$. Observations of nitrite + nitrate $\left(\mathrm{NO}_{2}+\mathrm{NO}_{3},\left[\mathrm{mmol} \mathrm{N} \mathrm{m}^{-3}\right]\right)$, chlorophyll $a(\mathrm{CHL} a$, $\left.\left[\mathrm{mg} \mathrm{m}^{-3}\right]\right)$ and ${ }^{14} \mathrm{C}$-primary production $\left(P P,\left[\mathrm{mg} \mathrm{C} \mathrm{m}^{-3} \mathrm{~d}^{-1}\right]\right)$ together with the optimal model solutions (grey lines). (a) Experiment A1 with biweekly monthly varying mixed-layer depths $M_{\mathrm{obs}}$, derived from observed temperature profiles. (b) Experiment A2 with weekly varying mixed-layer depths $M_{\text {week }}$, derived from the temperature profiles of the 3D-model. 


\section{Biomass A1 and A2}
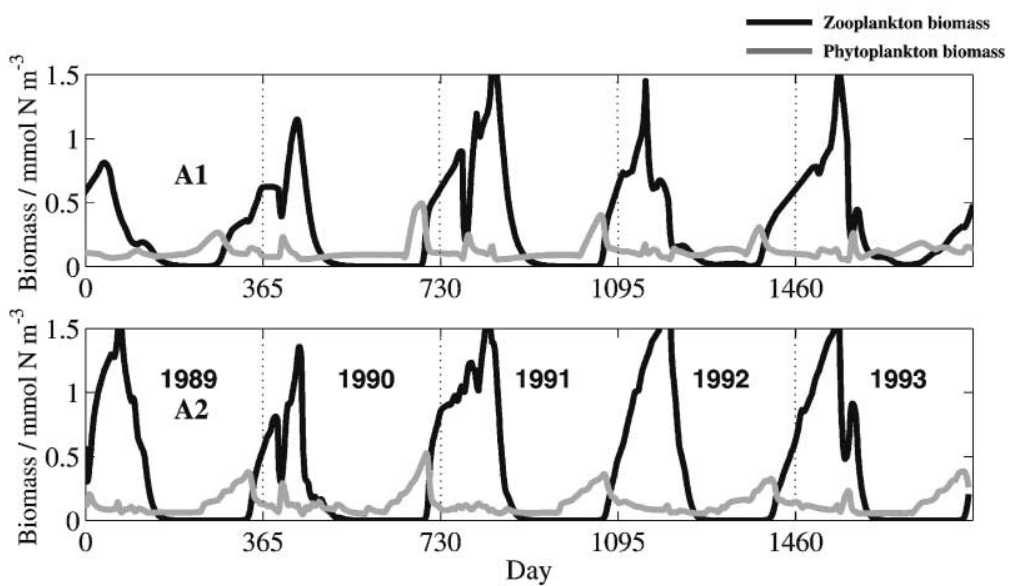

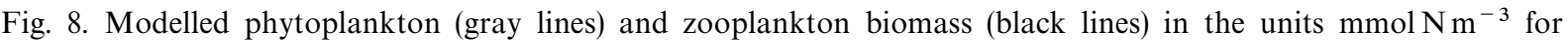
experiments A1 and A2, using the mean optimal parameter estimates $p_{v}^{\text {mean }}$. There were no constraints on zooplankton biomass in both experiments.

modelled zooplankton. Therefore, a large fraction of the organic nitrogen, fixed by the phytoplankton, was simply transferred into the zooplankton compartment via excessive grazing. The modelled zooplankton biomass yielded concentrations larger than $1 \mathrm{mmol} \mathrm{N} \mathrm{m}^{-3}$ every year. In experiment A1 a maximal value of $1.72 \mathrm{mmol} \mathrm{N} \mathrm{m}^{-3}$ was reached in 1991.

\subsubsection{Experiment A3: Observed sub-mixed layer $\mathrm{NO}_{2}+\mathrm{NO}_{3}$ concentration}

We learned from the previous experiments that the modelled primary production was too low during summer and that the remineralization was insufficient. The modelled productivity was mainly due to entrained "new" nutrients from below the mixed layer. The parameterizations of the deep $N_{D}$ produced concentrations $N_{D}>0.05 \mathrm{mmol} \mathrm{N} \mathrm{m}^{-3}$ during summer periods. But in reality the depletion of nitrate and nitrite was always observed to reach depths greater than the mean mixed layer during summer. In experiment A3 we took account of individual observations of $\mathrm{NO}_{3}+\mathrm{NO}_{2} 1 \mathrm{~m}$ below the actual mixed layer to provide a more realistic value of $N_{D}$. The observed values were linearly interpolated between the dates of observation. As a consequence a sub-mixed-layer concentration of $N_{D}$ close to the observations entered the model. Because of the new $N_{D}$ we expect to find parameter estimates that produce a feasible solution for the model with less zooplankton and an enhanced summer productivity, due to a rapid nutrient recycling. Like in experiments TE and A1 the applied mixed layer depths were $M_{\mathrm{obs}}$.

3.1.3.1. Results of experiment A3. With the optimization a best cost function value of $J_{\text {best }}=J^{N}+$ $J^{\mathrm{CHL}}+J^{\mathscr{P P P}}+J^{\text {prior }}=0.612+4.690+1.197+0.012=6.511$ was found, with a moderate fit to the nitrite + nitrate data. The same criteria on the acceptable region were applied as in experiments A1 and A2. The optimal estimates of the remineralization parameters, $\Omega$ and $\gamma$, were disappointing. We expected to permanently achieve high optimal estimates for these two parameters, being well 

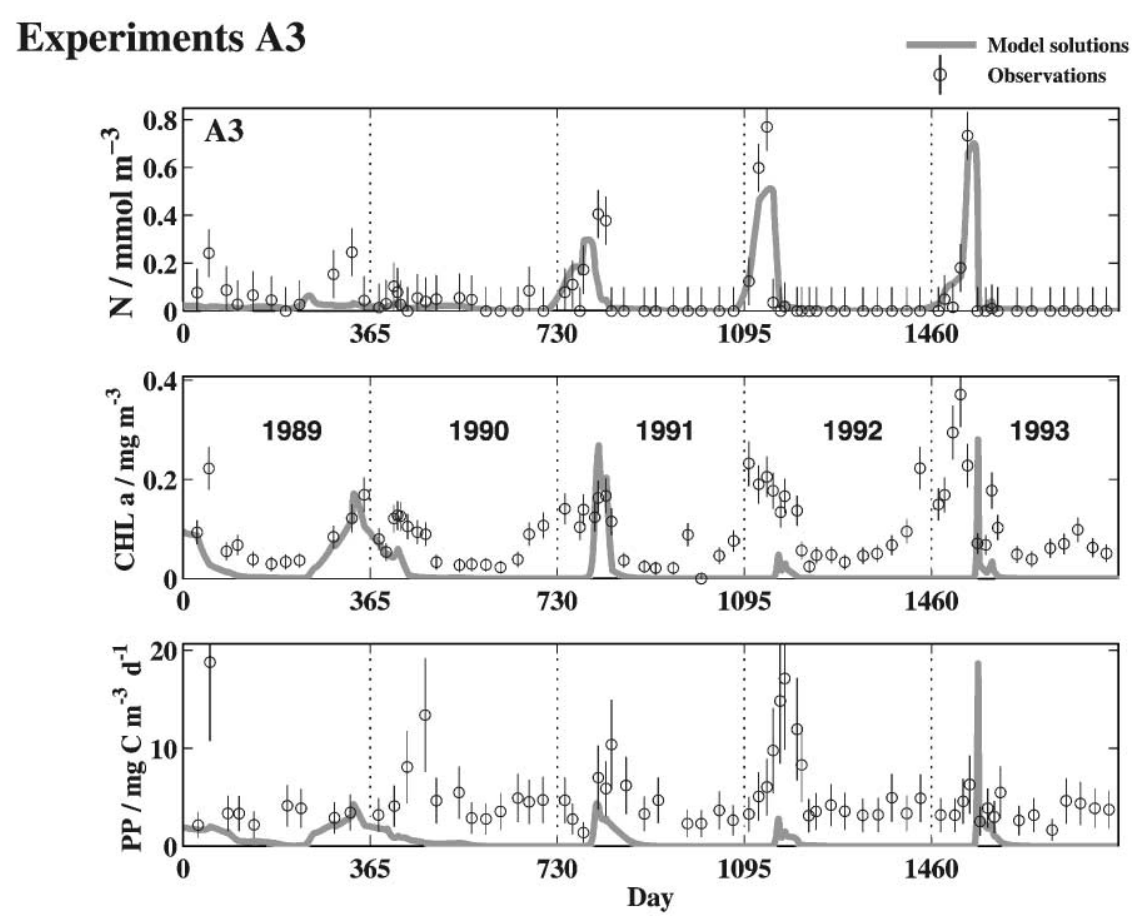

Fig. 9. Experiment A3. Observations of nitrite + nitrate $\left(\mathrm{NO}_{2}+\mathrm{NO}_{3},\left[\mathrm{mmol} \mathrm{N} \mathrm{m}{ }^{-3}\right]\right)$, chlorophyll a (CHL $a$, $[\mathrm{mg}$ $\left.\mathrm{m}^{-3}\right]$ ) and ${ }^{14} \mathrm{C}$-primary production $\left(P P,\left[\mathrm{mg} \mathrm{Cm}^{-3} \mathrm{~d}^{-1}\right]\right.$ ) together with the optimal model solutions (gray lines). Because of the rapid depletion of phytoplankton biomass the zooplankton could not respond. Consequently, no zooplankton biomass developed $(H=0)$.

constrained. However, the mean estimate of the phytoplankton remineralization parameter resulted in $\gamma=0.731 \mathrm{~d}^{-1}$, which is a higher estimate than obtained in experiments A1 and A2. Like the remineralization rates, the zooplankton parameters could not be sufficiently well constrained. The final estimates of the maximum grazing and prey capture rates were close to the initial guesses.

The model results that were produced with the optimal parameter values showed little seasonal variability; Fig. 9. Entrained $N$ could be reproduced fairly well but the deep nutrient concentrations did not accomplish any productivity immediately after the spring blooms. Small peaks in the modelled chlorophyll concentrations simply responded to the increase in $N$ during early spring periods. After that response the system collapsed and rapidly lacked remineralized nutrients. No zooplankton biomass developed, yielding $H=0 \mathrm{mmol} \mathrm{N} \mathrm{m}^{-3}$ at all times. The modelled zooplankton could not respond to the fast increase and decrease of the phytoplankton biomass. Because the optimal solution failed to build up any zooplankton biomass, the ecosystem was completely controlled by the nutrient availability during spring. This situation corresponds to a perfectly bottom-up controlled ecosystem and is in strong contrast with experiments A1 and A2, where the optimal solutions resulted in a top-down controlled ecosystems. The mean primary production amounted to $\overline{\mathscr{P} P}=8 \mathrm{gC} \mathrm{m}^{-2} \mathrm{yr}^{-1}$ which is much lower than that reached in experiments $\mathrm{A} 1$ and $\mathrm{A} 2$. 


\subsection{Experiment B: inclusion of zooplankton constraint}

Experiments A1 and A2 clearly demonstrated that simulated high zooplankton abundances resulted when the BATS measurements of chlorophyll, ${ }^{14} \mathrm{C}$-production and $\mathrm{NO}_{3}+\mathrm{NO}_{2}$ were assimilated into the three compartment model. Optimal model solutions, with zooplankton biomass exceeding that of phytoplankton, do not confirm the knowledge about the general functioning of the ecosystem near Bermuda. Unfortunately, only very few zooplankton observations are available at BATS. Zooplankton measurements were reported by Caron et al. (1995) fall into the period of model integration (August 1989 and March-April 1990). Nitrogen biomass of heterotrophic nanoplankton, together with microplankton, was obtained for the assimilation experiment, and a constant standard deviation of $\sigma_{\text {zoo }}=0.01 \mathrm{mmol} \mathrm{N} \mathrm{m}^{-3}$ was assumed. As we could see from experiment A2, an increased variability of mixed-layer depths enhanced the primary production. Consequently, we reconsidered the available weekly depths $M_{\text {week }}$, derived from the 3D-model.

\subsubsection{Results $B$}

The best cost function value achieved after the optimizations in experiment $\mathrm{B}$ was four times higher than those of $\mathrm{A} 1$ and $\mathrm{A} 2, J_{\text {best }}=J^{N}+J^{\mathrm{CHL}}+J^{\mathscr{P P S}}+J^{\mathrm{zoo}}+J^{\text {prior }}=0.881+8.400+$

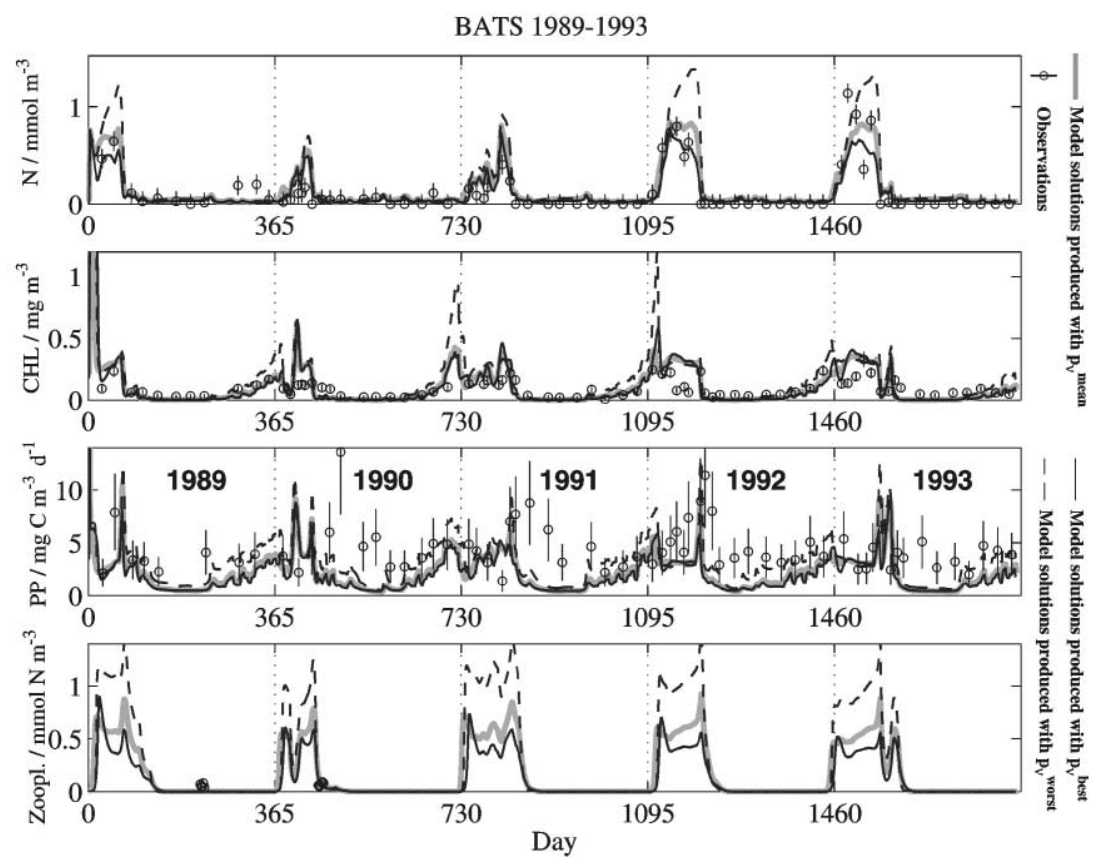

Fig. 10. Experiments B. Observations of nitrite + nitrate $\left(\mathrm{NO}_{2}+\mathrm{NO}_{3},\left[\mathrm{mmol} \mathrm{Nm}^{-3}\right]\right)$, chlorophyll $a$ (CHL $a$, $\left.\left[\mathrm{mg} \mathrm{m}^{-3}\right]\right){ }^{14} \mathrm{C}$-primary production $\left(P P,\left[\mathrm{mg} \mathrm{C} \mathrm{m}^{-3} \mathrm{~d}^{-1}\right]\right)$ and zooplankton biomass (Zoopl, $\left.\left[\mathrm{mmol} \mathrm{N} \mathrm{m}{ }^{-3}\right]\right)$. Zooplankton observations (heterotrophic nano- and microplankton from August 1989 and March/April 1990) were taken from Caron et al., 1995). Model solutions, produced with $p_{v}^{\text {mean }}$ are represented by the bold gray lines (note that the calculated mean values produce an artificially combined parameter set which results in $J_{\text {mean }}=23.443$ ). Solutions that were produced with $p_{v}^{\text {best }}$ (black line) and $p_{v}^{\text {worst }}$ (dashed line) are shown in addition. 


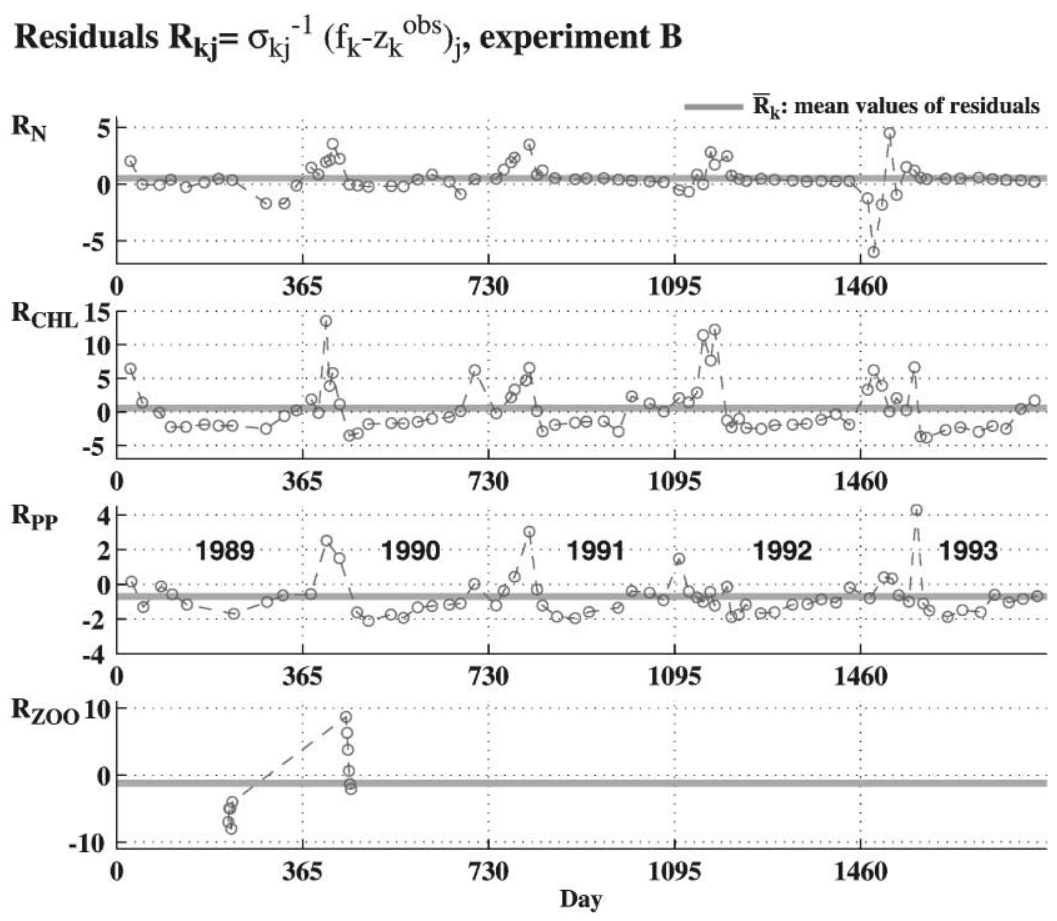

Fig. 11. The weighted residuals $R_{k j}$ [dimensionless] of experiment B represent the final model-data misfits at all observational times $j$, when the model solutions were produced with the parameter estimates $p_{v}^{\text {mean }}$. The remaining misfits between optimal model results and observations are weighted by their corresponding standard deviations, which simplifies a direct comparison. A high residual indicates a large contribution to the cost function at that time of observation. Residuals $R_{N}, R_{\mathrm{CHL}}, R_{\mathrm{PP}}$ and $R_{\mathrm{zoo}}=$ "o". Mean of the residuals = "gray lines".

$1.062+11.666+0.000=22.009$. This was not very surprising, since the additional zooplankton constraint produced the largest contribution to the final cost function. The cost function values of the initial parameter guesses typically ranged from $J \approx 60$ to 1000 . Again the $\Delta J$-criterion was applied for an a posteriori region of all parameter solutions. With this criterion only $n=8$ solutions could be considered, with cost function values smaller than $J<27.511$.

Table 4 lists the optimal parameter estimates. The mean maximum growth rate $p_{1}^{\text {mean }}=\mu_{\mathrm{m}}=2.187 \mathrm{~d}^{-1}$ was lower than in experiment A2 $\left(p_{1}^{\text {mean }}=\mu_{\mathrm{m}}=2.980 \mathrm{~d}^{-1}\right)$ without the zooplankton constraint. In the preferred optimally modelled ecosystem, phytoplankton was essentially controlled by the grazing of the herbivores. Top-down controlled ecosystems already were obtained in experiments A1 and A2. This corresponds with relatively low estimates for the phytoplankton loss parameter $\Phi_{p}\left(\Phi_{p}^{\text {mean }}=0.022 \mathrm{~d}^{-1}\right.$ and $\left.\Phi_{p}^{\max }=0.031 \mathrm{~d}^{-1}\right)$. Such a result was unexpected, because final estimates were hoped to converge towards high phytoplankton mortality values.

Model solutions, corresponding to the optimal parameter estimates, are illustrated in Fig. 10. The worst parameter values belong to the optimal solution that could fulfill the $\Delta J$ - criterion at least. The best solution yielded the lowest zooplankton biomasses, if compared with experiments 
A1 and A2 (it decreased by a factor of 3). Although the grazing pressure was reduced in this experiment the modelled mean primary production could be increased without increasing chlorophyll concentrations, $\overline{\mathscr{P P}}=62 \mathrm{gC} \mathrm{m}^{-2} \mathrm{yr}^{-1}$ for the best parameters and $\overline{\mathscr{P} \mathscr{P}}=66 \mathrm{gC} \mathrm{m}^{-2} \mathrm{yr}^{-1}$ for the mean estimates.

To investigate systematic model errors more closely in experiment $\mathrm{B}$, the misfits were analysed. Model solutions were generated with the best parameter estimate; see Table 4, and the corresponding weighted residuals $\mathscr{R}_{k j}$ for each type $k$ of observation were determined at observational times $j$ :

$$
\mathscr{R}_{k j}=\frac{1}{\sigma_{k j}}\left(f(y)_{k}-z_{k}^{\mathrm{obs}}\right)_{j} .
$$

Weighted residuals have no units and may therefore simplify a direct comparison. Fig. 11 illustrates the computed residuals for each type of observation. The residuals of the chlorophyll $\mathscr{R}_{2 j}=R_{\mathrm{CHL}}$ show highest values during spring. The high positive values of $R_{\mathrm{CHL}}$ indicate an overestimation of the chlorophyll $a$ concentrations. A simultaneous increase can be seen in the residuals of primary production $R_{\mathrm{PP}}$. When the phytoplankton biomass is overestimated, indicated by $R_{\mathrm{CHL}}$, the production is likely to be overrated; see Eq. (13). Another discrepancy between model and observation could be identified from $R_{\mathrm{PP}}$. It seemed already obvious from Fig. 10 that the modelled primary production is systematically too low during the summer period. The most negative residuals of $R_{\mathrm{PP}}$ refer to misfits immediately after the decline of the chlorophyll concentrations. The residuals of the zooplankton $R_{\text {zoo }}$ illustrate how the observations were under- as well as overestimated by the model.

\section{Concluding discussion}

\subsection{Parameters and model results}

The main objective of our study is to recover an optimal set of parameters for an adequate ecosystem model. This paper does not provide such an appropriate model, but shows where the simple equations need to be improved. The presented results base on an experimental approach that differs from other studies (Hurtt and Armstrong, 1996; Spitz et al., 1998). Here, only a simple three-compartment ecosystem model has been used for the assimilation of BATS data, including interannual variabilities over a 5-yr period. From other modelling studies we already learned how difficult it is to resolve the most relevant biological processes correctly at BATS and to justify the proposed model complexities (e.g. Fasham et al., 1990; Hurtt and Armstrong, 1996, 1999; Spitz et al., 1998). Our experiments also demonstrate how data-assimilation can lead to wrong model results although the observed data, which enter the model-data misfit function apparently can be fitted. Such optimal fits are insufficient to really validate the applied ecosystem model equations. Having a relatively simple model, we could easily realize that these optimal results were not biologically plausible. The detection of implausible features can quickly become more difficult in more complex models.

The assimilation experiments lead to high maximum growth rates $\mu_{\mathrm{m}}$, combined with relatively low estimates of the half-saturation constant $k$. An underestimation of the primary production by 
the model (especially during the summer periods) produces small estimates of $k$, in order to assure a high nutrient utilization for low $N$ concentrations. As $k$ decreases, the uptake rates get closer to $u=1 \mathrm{~d}^{-1}$, the adjoint model then provides a gradient information for $\mu$ such that the estimates are increased by the minimization algorithm.

The optimally determined maximum growth rates always ranged between $\mu_{\mathrm{m}}=2-3 \mathrm{~d}^{-1}$, which match the growth rates determined from the formula of Eppley (1972). Our optimized values are also comparable to the values assumed by Fasham et al. (1990). Hurtt and Armstrong (1996) determined smaller growth rates of $\mu_{\mathrm{m}}=1.2$ and $0.48 \mathrm{~d}^{-1}$. But a direct comparison is difficult because they included an allometric relationship that resulted in nutrient-limited growth rates for their smallest phytoplankton of $\mu_{\mathrm{m}}=1.26 \mathrm{~d}^{-1}$ as well as to values of $\mu_{\mathrm{m}}=4.86 \mathrm{~d}^{-1}$ for growth under light limitation. Their optimal estimates of the photosynthetic efficiency $\alpha$ were relatively high. We received comparable estimates, mostly $\alpha>0.3 \mathrm{~m}^{2} \mathrm{~W}^{-1} \mathrm{~d}^{-1}$, although these high values deviate from the value derived by Fasham et al. (1990), who assumed an initial slope of $\alpha=0.025 \mathrm{~m}^{2} \mathrm{~W}^{-1} \mathrm{~d}^{-1}$.

The resulting grazing parameters $g$ and $\varepsilon$ mostly reached their upper penalty limits, as a consequence of high productivity combined with low chlorophyll concentrations in experiments A1, A2 and $\mathrm{B}$. But these optimal grazing rates created a large concentration of zooplankton biomass only when the assimilation efficiency $\beta$ for the herbivores was high as well. Experiment B showed how the additional zooplankton constraint produced a minimal estimate of $\beta=0.674$. From Fig. 10 it can be seen how the zooplankton abundances could be damped with the decrease of the assimilation efficiency. The sensitivity of the modelled zooplankton to variations in $\beta$ was greater than those of the grazing parameters $g$ and $\varepsilon$.

The estimates of optimal remineralization parameters $\Omega$ and $\gamma$ was a problem. In experiment B the optimal estimates of $\Omega$ and $\gamma$ were best constrained. The goodness of estimation can be judged from the relations $r=\left(p_{v}^{\max }-p_{v}^{\min }\right) /\left(p_{v}^{\mathrm{u}}-p_{v}^{1}\right)$, which tend towards 1 for bad and towards 0 for good estimates. Especially the estimates of the phytoplankton remineralization rate $\gamma$ could be improved, from $r=1.12$ in experiment A2 to $r=0.69$ in experiment B. Primary production data and chlorophyll concentrations did not constrain these parameters. Remineralization in the model needs to be reconsidered and for future assimilation experiments we would introduce constraints on the averaged $f$-ratio as well. The modelled process of phytoplankton remineralization is a product of the phytoplankton loss parameter $\Phi_{p}$ and the remineralization parameter $\gamma$. If $\Phi_{p}$ remains uncertain then it is impossible to restrict $\gamma$. Hurtt and Armstrong (1996) obtained better results for remineralization by adding an extra recycling pool. Their recycling compartment is a sink for phytoplankton biomass and a potential source for ammonium, which is then available for phytoplankton growth (primary production due to recycled nutrients). To limit the abundance of phytoplankton within their size classes, they recovered high phytoplankton mortalities, ranging from 0.43 to $1.13 \mathrm{~d}^{-1}$. Optimal phytoplankton mortalities obtained in our study were one order of magnitude smaller. As long as there were no constraints on zooplankton biomass, the optimized model favoured a solution with losses due to grazing rather than to other processes. In experiment A2, which provided the lowest final cost function value compared to the two other experiments with real data, the observations were relatively well reproduced by the model counterparts, but for the wrong reasons. These model fits were only possible with maximal zooplankton biomasses of $>1.5 \mathrm{mmol} \mathrm{N} \mathrm{m}^{-3}$ in late spring that exceed observed concentrations $H \approx 0.05 \mathrm{mmol} \mathrm{N} \mathrm{m}^{-3}$ by roughly a factor of 30 . 
The regard of nitrite + nitrate, primary production together with chlorophyll data for the cost function still requires additional constraints on zooplankton, especially if some other phytoplankton sinks, like small particle formation and sinking, cannot be resolved by the models. If zooplankton is implicitly modelled the loss terms for phytoplankton biomass due to grazing should be constrained. Otherwise, zooplankton grazing and biomass will dominate the system while chlorophyll and primary production data seem to be surprisingly well reproduced by their model counterparts.

\subsection{Phytoplankton production}

The assimilated BATS data exhibit a distinct time lag between the maximum of ${ }^{14} \mathrm{C}$-production and the maximum of chlorophyll concentration. Since the modelled primary production is derived from nitrogen-based productivity, our experiments were not able to adopt these observed features. Malone et al. (1993) observed variations in phytoplankton productivity that were independent of the measurable chlorophyll concentrations in the euphotic zone. They attributed this phenomenon to the shift from a production that is limited by the total availability of entrained deep "new" nutrients to a production limited by the rate of nutrient regeneration. Another possible explanation for high carbon assimilation ratios despite low biomass production might be due to exudation of carbohydrates and the formation of polymer carbohydrate particles (Wells, 1998) in the ocean (e.g., TEP, Alldredge et al., 1993). An overestimation of the particulate production rates by up to $30 \%$ was reported by Karl et al. (1998). They found an evidence that ${ }^{14} \mathrm{C}$-labeled dissolved organic carbon adsorped onto glass fibre-filters. In this case the nitrogen-based phytoplankton productivity does not equal the carbon-based productivity measurements. A simple conversion of nitrogen to carbon with a constant $\mathrm{C}: \mathrm{N}$ ratio would be a severe model error. For data assimilation it is necessary to consider the effects of these processes and errors.

The direct comparison of measured ${ }^{14} \mathrm{C}$-production data with modelled phytoplankton production rates is apparently inadequate when a constant $\mathrm{C}: \mathrm{N}$ ratio is assumed. The consideration of carbon exudation, producing variable $\mathrm{C}: \mathrm{N}$ ratios for productivity, should improve the assimilation of ${ }^{14} \mathrm{C}$-production data into the ecosystem model.

\subsection{Phytoplankton export}

Nitrogen fixation was not considered but is believed to cause higher chlorophyll concentrations. The modelled chlorophyll concentrations already remain too high if the herbivorous grazing pressure were reduced. In this case we must introduce a term that enhances the export of phytoplankton biomass. As a rudimentary first step, a quadratic phytoplankton loss can be added to the linear loss term, as introduced by Doney et al. (1996). This enhances phytoplankton losses with a rapid increase in biomass. Gardner (1997) points out that the combination of settling particle aggregates and diurnal changes in mixed-layer depths can be a very effective mechanism to remove organic material from the upper ocean. This would be appropriate to an increased export during March and April when stratification commences and diurnal changes in mixed-layer depths are maximal. Particle aggregates can be formed from phytoplankton cells, preferentially diatoms (Alldredge and Gottschalk, 1989). But the relatively low chlorophyll concentrations near Bermuda suggest that aggregation is unlikely. Nevertheless, together with additional particles, such as 
polymer carbohydrates, aggregation might be far more effective due to increased collision rate and adherence (Engel, 2000).

With respect to assimilation experiments of surface chlorophyll data we may need to account for additional processes of phytoplankton export from the upper ocean layers. From the mentioned coincidence of highest productivity and a rapid chlorophyll decrease we speculate on a connection of both events.

\subsection{Deep nutrient availability}

Except for experiment A3 the availability of the deep nutrient concentration $N_{D}$ was parameterized. The parameterization produced $N_{D} \approx 0.1 \mathrm{mmol} \mathrm{N} \mathrm{m}^{-3}$ during nutrient depletion in the summer periods (a similar value was determined by Hurtt and Armstrong, 1996), whereas it could become $N_{D}>4 \mathrm{mmol} \mathrm{N} \mathrm{m}{ }^{-3}$ when deep mixing commenced. Experiments with the constant gradient approach, as assumed by Hurtt and Armstrong (1996), did not produce model results as close to the observations as for experiments A1, A2 and B. These optimizations with a constant gradient parameterization led to high estimates of the mixing rate $m_{\mathrm{r}}$ which increased the entrained dissolved $N$ and the CHL a concentrations during summer. Fig. 12 shows the different nutrient availabilites $\left(N_{D}\right.$ derived from parameterizations and prescribed sub-mixed layer $\mathrm{NO}_{2}+\mathrm{NO}_{3}$ concentrations). The parameterization, chosen for this study, considered the remineralization process below the mixed layer, which could not be resolved by the model. Such an approach could

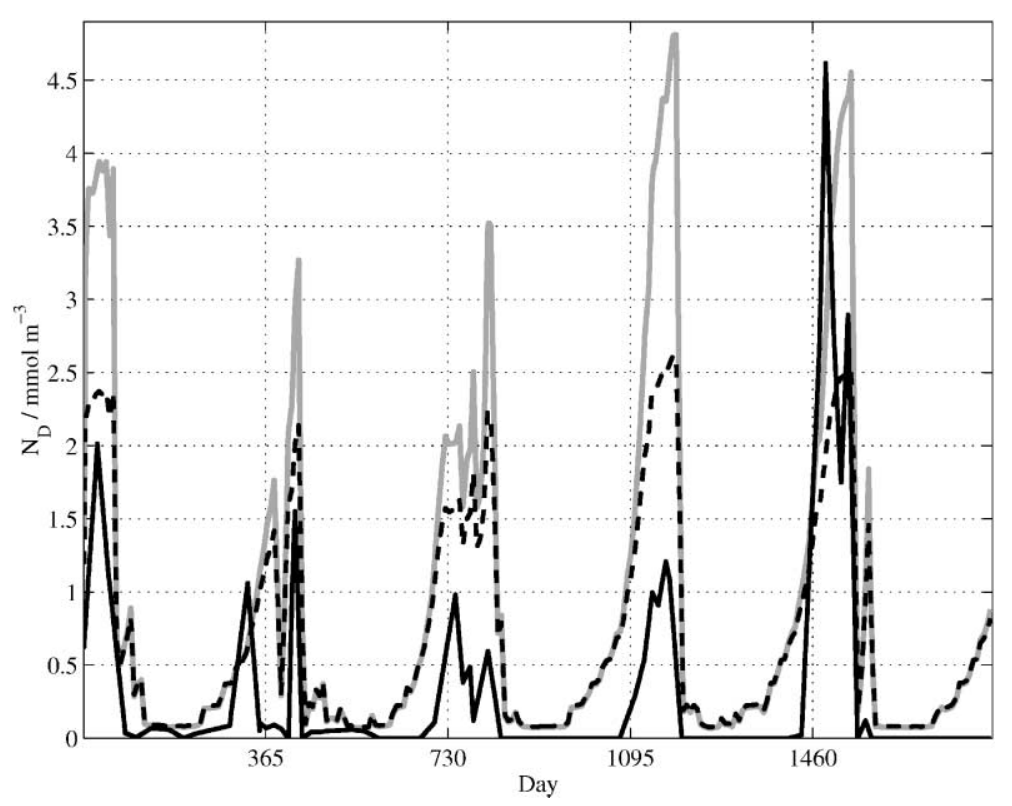

Fig. 12. Different deep $N_{D}$ concentrations. Modelled $N_{D}$ concentrations derived from: (1) Black dashed line: parameterization with a constant gradient of $0.0125 \mathrm{mmol} \mathrm{N} \mathrm{m}^{-4}$; (2) Gray solid line: modified parameterization with increased $N_{D}$ during deep mixing events; (3) Black solid line: sub-mixed-layer concentrations. Because the mixed layer reached depths down to about $M \approx 200 \mathrm{~m}$ the deep dissolved nitrogen concentration $N_{D}$ could increase by a factor of 2 , if compared with the constant gradient parameterization. 
be interpreted as a source of new nutrients to deeper layers. When deep mixing starts in late autumn, the turbulent flux of nitrogen into the mixed layer is increased.

The formulation of the lower boundary conditions for an ecosystem model is a difficult task and requires further investigations. But, if the chosen ecosystem model configuration should be applicable to various places in the ocean it would be better to extend the resolution of the model. However, the parameterization of the deep nutrient availability can be avoided if a model with vertical resolution is constructed, e.g., such as the physical-biological model of Doney et al. (1996).

\subsection{Optimization}

The a posteriori error distribution for the parameter estimates was not known when the twin experiment was started. If we had postulated a normal distribution, we could have determined an a posterior covariance matrix from a discrete Hessian matrix, which can be calculated with the adjoint model (Marotzke and Wunsch, 1993; Schiller, 1995; Gunson and Malanotte-Rizzoli, 1996). But, from the mean parameter vector and the extensions of the acceptable parameter space we can see that the parameter solutions are not normally or equally distributed. This was especially the case for the zooplankton parameters. For example, in experiment A2, the minimal estimate for the maximum grazing rate was $p_{5}^{\min }=0.588 \mathrm{~d}^{-1}$, but the mean $p_{5}^{\text {mean }}=1.031 \mathrm{~d}^{-1}$ is much closer to the maximal estimate of $p_{5}^{\max }=1.176 \mathrm{~d}^{-1}$. Nevertheless, Fig. 10 indicated that the model solutions, corresponding to the a posteriori determined mean parameter values were closely related to the best estimates, although the mean parameter values (as a set of parameters $p_{v}^{\text {mean }}$ ) were artificially combined.

During the twin experiment TE more than $70 \%$ of the optimizations converged to a local minimum although the corresponding solution had no active biology. It produced model results without phytoplankton and zooplankton biomass $(P=0$ and $H=0$, whereas $N>0)$. The differences between parameter estimates of the local and the global minimum were obviously due to variations of the maximum growth rate $\mu_{\mathrm{m}}$. For low values of $\mu_{\mathrm{m}}<0.6 \mathrm{~d}^{-1}$ the depth-integrated growth function inhibited phytoplankton growth completely. This produced a local minimum in which the zooplankton assimilation efficiency $\beta$ together with the photosynthetic efficiency $\alpha$ could not be recovered in contrast to the global minimum solution with $\mu_{\mathrm{m}} \approx 2 \mathrm{~d}^{-1}$. If the maximum growth rate was slowly increased from $\mu_{\mathrm{m}}=0.3$ to $\mu_{\mathrm{m}}=0.8$, it would first produce a larger misfit to the pseudo-observations, changing from one model solution (with $\mathrm{P}$ and $Z=0$ ) to the other (with decreased $\mathrm{N}, \mathrm{P}$ and $H>0$ ). From one- and two-dimensional variational experiments we realized large asymmetries in the cost function (e.g. Fig. 6b), if compared with an ideal parabola. Such asymmetries in the cost function are typical for ecosystem models. When the weights were differently chosen (e.g., similar to Lawson et al., 1996), the asymmetries could not be reduced. Due to these asymmetries the convergence criteria for the minimization algorithm differed, depending on the initial guesses. If the initial parameter guess was located on a relatively flat cost function region, the algorithm would assume a low sensitivity of the cost function to variations of the parameter and the convergence criterion would be sharp. Despite the fact that large asymmetries of the cost function were present, the twin experiment proved the applicability of the adjoint method and the recovery of optimal parameter values in combination with the definition of an acceptable region. Identical twin experiments had been performed with no noise on the synthetically produced data and the reference parameter values were totally resolved, starting from different initial guesses. 
From the assimilation experiments with real observations we concluded that hundreds of individual optimizations may be necessary to find the global minimum solution. Furthermore, the model solution produced with the mean parameter values can be utilized as an optimal model fit to the observations. This implies the applicability of stochastic minimization procedures, such as genetic algorithms (Holland, 1962; Goldberg, 1989), which give an average of the final parameter estimates.

The final value of the cost function alone was not sufficient to determine whether our model describes the observations in a consistent way. The residuals, which remain between the data and the optimal model solution, also must be investigated. If the model were consistent with the statistical assumptions about the observational error variances $\sigma_{k}^{2}$, the residuals would have had a white noise character. Fig. 11 clearly showed that this was not the case. The non-random distribution of the residuals indicated systematic deficiencies of the model, such as the underestimation of primary production after the decrease of the chlorophyll concentrations and the missing of phytoplankton export mechanisms. Our ultimate goal will be to determine the necessary model complexity that is required to achieve a model trajectory and residuals consistent with our assumptions about observational errors.

\section{Acknowledgements}

We gratefully acknowledge the BATS group who provided us with the data used in this paper. We like to thank two reviewers who greatly helped to improve the paper. We are also very grateful to Geoff Evans for his helpful comments on the manuscript. We thank Friedrich Wagner from the department of theoretical physics who provided us with the minimization algorithm. Special thanks to Anja Engel who assisted in biological questions and Markus Meier for his advices during the adjoint code construction.

The support of the BMBF through the German JGOFS project is gratefully acknowledged.

\section{Appendix A}

\section{A.1. The adjoint model}

The extension of the cost function $J$ by adding the product of Lagrange multipliers with the strong constraints gives a Lagrange-function:

$$
\mathscr{L}=J\left(\mathbf{y}, \mathbf{z}^{\mathrm{obs}}, \mathbf{p}_{0}, \mathbf{p}^{\mathrm{est}}\right)+\int \lambda^{T}\left(\frac{\mathrm{d} \mathbf{y}}{\mathrm{d} t}-F\left(\mathbf{y}, \mathbf{p}^{\mathrm{est}}\right)\right) \mathrm{d} t
$$

which satisfies the relation

$$
\frac{\delta \mathscr{L}}{\delta \mathbf{y}}=\frac{\partial \mathscr{L}}{\partial \mathbf{y}}-\frac{\mathrm{d}}{\mathrm{d} t} \frac{\partial \mathscr{L}}{\partial \mathbf{y}^{\prime}}=0
$$


when the optimal parameters $p_{v}$ are found. Solving Eq. (A.2) for the Lagrange multipliers gives the adjoint equations

$$
-\frac{\mathrm{d}}{\mathrm{d} t} \lambda=\lambda^{T} \frac{\partial F}{\partial \mathbf{y}}-\frac{\partial J}{\partial \mathbf{y}}
$$

for a time-dependent model. The gradient of $\mathscr{L}$ with respect to the parameters $p_{i}$ were calculated after integrating Eq. (A.3) and solving for the Lagrange multipliers. New parameter values $p_{v}^{\text {est }}$ were estimated by supplying a variable metric algorithm with the values of $\partial \mathscr{L} / \partial p_{v}, p_{v}$, and $\mathscr{L}$. The cost function $J$ was minimized when the gradients had converged to zero.

\section{A.1.1. The Lagrange function}

The Lagrange function formulated for the discrete prognostic equations

$$
\begin{aligned}
\mathscr{L}= & J+\sum_{i} \lambda_{i}^{P}\left[\frac{1}{\tau}\left(P_{i+1}-P_{i}\right)-\left(\mu u_{i}-\Phi_{P}-h\right) P_{i}+G\left(P_{i}\right) H_{i}\right] \\
& +\sum_{i} \lambda_{i}^{H}\left[\frac{1}{\tau}\left(H_{i+1}-H_{i}\right)-\left(\beta G-\Phi_{H}-h\right) H_{i}\right] \\
& +\sum_{i} \lambda_{i}^{N}\left[\frac{1}{\tau}\left(N_{i+1}-N_{i}\right)+\left(\mu u_{i}-\gamma \Phi_{P}\right) P_{i}-\left[(1-\beta) G+\Phi_{H}\right] \Omega H_{i}-h\left(N_{D}-N_{i}\right)\right]
\end{aligned}
$$

with $h=\frac{m_{\mathrm{r}}+w_{\mathrm{e}}}{M}$.

\section{A.1.2. The adjoint equations}

A.1.2.1. Derivatives with respect to the state variable $P_{i}$ :

$$
\begin{gathered}
\frac{\partial \mathscr{L}}{\partial P_{i}}=\frac{\partial J}{\partial P_{i}}+\frac{1}{\tau}\left(\lambda_{i-1}^{P}-\lambda_{i}^{P}\right)-\lambda_{i}^{P}\left(\frac{\partial_{\mu}}{\partial P_{i}} u_{i} P_{i}+\mu u_{i}-\Phi_{P}-h+\frac{\partial G}{\partial P_{i}} H_{i}\right) \\
-\lambda_{i}^{H} \beta \frac{\partial G}{\partial P_{i}} H_{i}+\lambda_{i}^{N}\left(\frac{\partial \mu}{\partial P_{i}} u_{i} P_{i}+\mu u_{i}-\gamma \Phi_{P}-\Omega(1-\beta) \frac{\partial G}{\partial P_{i}} H_{i}\right)=0 .
\end{gathered}
$$

The Lagrange multipliers need to be integrated backward in time starting from the date of the last observation:

$$
\begin{aligned}
\Rightarrow \lambda_{i-1}^{P}= & {\left[-\frac{\partial J}{\partial P_{i}}+\lambda_{i}^{P}\left(\frac{\partial \mu}{\partial P_{i}} u_{i} P_{i}+\mu u_{i}-\Phi_{P}-h-\frac{\partial G}{\partial P_{i}} H_{i}\right)+\lambda_{i}^{H} \beta \frac{\partial G}{\partial P_{i}} H_{i}\right] \tau } \\
& <\sec 4>-\left[\lambda_{i}^{N}\left(\frac{\partial \mu}{\partial P_{i}} u_{i} P_{i}+\mu u_{i}-\gamma \Phi_{P}-\Omega(1-\beta) \frac{\partial G}{\partial P_{i}} H_{i}\right)\right] \tau+\lambda_{i}^{P} .
\end{aligned}
$$

A.1.2.2. Derivatives with respect to the zooplankton (herbivores) $H_{\mathrm{i}}$ :

$$
\frac{\partial \mathscr{L}}{\partial H_{i}}=\frac{\partial J}{\partial H_{i}}+\frac{1}{\tau}\left(\lambda_{i-1}^{H}-\lambda_{i}^{H}\right)+\lambda_{i}^{P}
$$




$$
\begin{gathered}
-\lambda_{i}^{H}\left(\beta G-\Phi_{H}-h\right)-\lambda_{i}^{N} \Omega\left((1-\beta) G+\Phi_{H}\right)=0 \\
\Rightarrow \lambda_{i-1}^{H}=\left[-\frac{\partial J}{\partial H_{i}}-\lambda_{i}^{P} G+\lambda_{i}^{H}\left(\beta G-\Phi_{H}-h\right)+\lambda_{i}^{N}\left(\Omega(1-\beta) G+\Phi_{H}\right)\right] \tau+\lambda_{i}^{H} .
\end{gathered}
$$

A.1.2.3. Derivatives with respect to $N_{i}$ :

$$
\frac{\partial \mathscr{L}}{\partial N_{i}}=\frac{\partial J}{\partial H_{i}}-\lambda_{i}^{P} \mu \frac{\partial u_{i}}{\partial N_{i}} P_{i}+\frac{1}{\tau}\left(\lambda_{i-1}^{N}-\lambda_{i}^{N}\right)+\lambda_{i}^{N} \sigma \frac{\partial u_{i}}{\partial N_{i}}+\lambda_{i}^{N} h=0
$$

with

$$
\frac{\partial u_{i}}{\partial N_{i}}=\frac{k}{\left(k+N_{i}\right)^{2}} \Rightarrow \lambda_{i-1}^{N}=\left[-\frac{\partial J}{\partial N_{i}}+\left(\lambda_{i}^{P}-\lambda_{i}^{N}\right) \mu \frac{k P_{i}}{\left(k+N_{i}\right)^{2}}-\lambda_{i}^{N} h\right] \tau+\lambda_{i}^{N} .
$$

A.1.2.4. Derivatives of the cost function $J$ with respect to the state variables:

$$
\begin{aligned}
& \frac{\partial J}{\partial P}=\frac{\partial J^{\mathscr{P P}}}{\partial P}+\frac{\partial J^{\mathrm{CHL}}}{\partial P}, \\
& \frac{\partial J^{\mathscr{P P}}}{\partial P}=\frac{1}{\sigma_{\mathscr{P} \mathscr{P}}^{2}}\left(R \mu u P-\mathscr{P} \mathscr{P}_{\mathrm{obs}}\right)\left(R \frac{\partial \mu}{\partial P} u P+R \mu u\right), \\
& \frac{\partial J^{\mathrm{CHL}}}{\partial P}=\frac{1}{\sigma_{\mathrm{CHL}}^{2}}\left(r_{\mathrm{CHL}} P-\mathrm{CHL}_{\mathrm{obs}}\right) r_{\mathrm{CHL}}, \\
& \frac{\partial J}{\partial N}=\frac{\partial J^{N}}{\partial N}+\frac{\partial J^{\mathscr{P} P}}{\partial N}+\frac{\partial J^{\mathrm{CHL}}}{\partial N}, \\
& \frac{\partial J^{\mathscr{P P}}}{\partial N}=\frac{1}{\sigma_{\mathscr{P} \mathscr{P}}^{2}}\left(R \mu u P-\mathscr{P} \mathscr{P}_{\mathrm{obs}}\right) R \mu P \frac{\partial u}{\partial N} \\
& \frac{\partial J^{\mathrm{CHL}}}{\partial N}=\frac{1}{\sigma_{\mathrm{CHL}}^{2}}\left(r_{\mathrm{CHL}} P-\mathrm{CHL}_{\mathrm{obs}}\right) \frac{\partial r_{\mathrm{CHL}}}{\partial N} P, \\
& \frac{\partial J^{\mathrm{N}}}{\partial N}=\frac{1}{\sigma_{\mathrm{din}}^{2}}\left(N-\left(\mathrm{NO}_{3}+\mathrm{NO}_{2}\right)^{\mathrm{obs}}\right) .
\end{aligned}
$$

\section{References}

Alldredge, A.L., Gottschalk, C., 1989. Direct observations of the mass flocculation of diatom blooms; characteristics, settling velocities and formation of diatom aggregates. Deep-Sea Research I 36 (2), 159-171.

Alldredge, A.L., Passow, U., Logan, B.E., 1993. The abundance and significance of a class of large, transparent organic particles in the ocean. Deep-Sea Research I 40, 1131-1140.

Brock, T.D., 1981. Calculating solar radiation for ecological studies. Ecological Modelling 14, 1-19.

Caron, D.A., Dam, H.G., Kremer, P., Lessard, E.J., Madin, L.P., Malone, T.C., Napp, J.M., Peele, E.R., Roman, M.R., Youngbluth, M.J., 1995. Deep-Sea Research I 42, 943-972. 
Cloern, J.E., Grenz, C., Videgar-Lucas, L., 1995. An empirical model of the phytoplankton: carbon ratio - the conversion factor between productivity and growth rate. Limnology and Oceanography 40 (7), $1313-1321$.

Doney, S.C., Glover, D.M., Najjar, R.G., 1996. A new coupled, one- dimensional biological-physical model for the upper ocean: applications to the JGOFS Bermuda Atlantic Time-series Study (BATS) site. Deep-Sea Research II 43, 625-651.

Ducklow, H.W., 1983. Production and fate of bacteria in the oceans. Bioscience 33, 494-501.

Eppley, R.W., 1972. Temperature and phytoplankton growth in the sea. Fishery Bulletin 17, 15-24.

Eppley, R.W., Peterson, J.S., 1979. Particulate organic matter flux and planktonic new production in the deep ocean. Nature 282, 677-680.

Engel, A., 2000. The role of transparent exopolymer particles (TEP) in the increase in apparent particle stickness $(\alpha)$ during the decline of a diatom bloom. Journal of Plankton Research 22, 485-497.

Evans, G.T., Parslow, J.S., 1985. A model of annual plankton cycles. Biological Oceanography 3, $327-347$.

Evans, G.T., 1999. The role of local models and data sets in the Joint Global Ocean Flux Study. Deep-Sea Research I 46, 1369-1389.

Fasham, M.J.R., Ducklow, H.W., McKelvie, S.M., 1990. A nitrogen-based model of plankton dynamics in the oceanic mixed layer. Journal of Marine Research 48, 591-639.

Fasham, M.J.R., 1995. Variations in the seasonal cycle of biological production in subarctic oceans: A model sensitivity analysis. Deep-Sea Research 42, 1111-1149.

Fasham, M.J.R., Evans, G.T., 1995. The use of optimization techniques to model marine ecosystem dynamics at the JGOFS station at $47^{\circ} \mathrm{N} 20^{\circ} \mathrm{W}$. Philosophical Transactions of the Royal Society of London 348, $203-209$.

Fletcher, R., Powell, M.J.D., 1963. A rapidly convergent descent method for minimization. Computer Journal 6, $163-168$.

Gardner, W.D., 1997. The flux of particles to the deep sea: methods, measurements, and mechanisms. Oceanography 10 (3), 116-121.

Grasshoff, K.M., Kremling, K., Ehrhardt, M., 1999. Methods of Seawater Analysis, 3rd Edition. Wiley-VCH, Weinheim, 600 pp.

Gunson, J.R., Malanotte-Rizzoli, P.M., 1996. Assimilation studies of open-ocean flows 1. Estimation of initial and boundary conditions. Journal of Geophysical Research 101 (C12), 28 457-28 472.

Gunson, J.R., Oschlies, A., Garcon, V., 1999. Sensitivity of ecosystem parameters to simulated satellite ocean colour data using a coupled physical-biological model of the North Atlantic. Journal of Marine Research 57, 613-639.

Harmon, R., Challenor, P., 1997. A Markov chain Monte Carlo method for estimation and assimilation into models. Ecological Modelling 101, 41-59.

Herbland, A., Le Bouteiller, A., Raimbault, P., 1985. Size Structure of phytoplankton biomass in the equatorial Atlantic Ocean. Deep-Sea Research I 32, 819-836.

Holland, J.H., 1992. Adaptation in Natural and Artificial Systems. A Bradford Book, The MIT Press, Cambridge, MA.

Hurtt, G.C., Armstrong, R.A., 1996. A pelagic ecosystem model calibrated with BATS data. Deep-Sea Research II 43, 653-683.

Hurtt, G.C., Armstrong, R.A., 1999. A pelagic ecosystem model calibrated with BATS and OWSI data. Deep-Sea Research I 46, 27-61.

JGOFS, 1996. Protocols for the JGOFS core measurements. Scientific Committee on Oceanic Research, International Council of Scientific Unions, Bergen, JGOFS Report No. 19, 170 pp.

Jung, T.E., Ruprecht, E., Wagner, F., 1998. Determination of cloud liquid water path over the oceans from Special Sensor Microwave/Imager (SSM/I) data using neural network. Journal of Applied Meteorology 37, 832-844.

Karl, D.M., Hebel, D.V., Bjorkman, K., Letelier, R.M., 1998. The role of dissolved organic matter exudation in the productivity of the oligotrophic North Pacific Gyre. Limnology and Oceanography 43, 1270-1286.

Lawson, L.M., Hofmann, E.E., Spitz, Y.H., 1996. Time series sampling and data assimilation in a simple marine ecosystem model. Deep-Sea Research II 43, 625-651.

Malone, C.M., Pike, S.E., Conley, D.J., 1993. Transient variations in phytoplankton productivity at the JGOFS Bermuda time series station. Deep-Sea Research 40 (5), 903-924.

Marotzke, J., Wunsch, C., 1993. Finding the steady state of a general circulation model through data assimilation: application to the North Atlantic Ocean. Journal of Geophysical Research 98, 20 149-20167. 
Matear, R.J., 1995. Parameter optimization and analysis of ecosystem model using simulated annealing: a case study at Station P. Journal of Marine Research 53, 571-607.

Michaels, A.F., 1995. Ocean time series research near Bermuda: the Hydrostation S time series and the Bermuda Atlantic time series (BATS) program. In: Powell, T.M., Steele, J.H. (Eds.), Ecological Time Series. Chapman \& Hall, London, UK, pp. 181-208.

Michaels, A.F., Knap, A.H., 1996. Overview of the US JGOFS Bermuda time-series study and the Hydrostation S program. Deep-Sea Research II 43, 157-198.

Morel, A., 1988. Optical modeling of the upper ocean in relation to its biogenous matter content (Case I waters). Journal of Geophysical Research 93, 10749-10768.

Navon, I.M., 1997. Practical and theoretical aspects of adjoint parameter estimation and identifiability in meteorology and oceanography. Dynamics of Atmosphere and Oceans 27, 55-79.

Oschlies, A., Garcon, V., 1998. Eddy-induced enhancement of primary production in a model of the North Atlantic. Nature 394, 266-269.

Oschlies, A., Garcon, V., 1999. An eddy-permitting coupled physical-biological model of the North Atlantic 1. Sensitivity to advection numerics and mixed layer physics. Global Biogeochemical Cycles 13, 135-160.

Platt, T., Harrison, W.G., 1985. Biogenic fluxes of carbon and oxygen in the ocean. Nature 318, 55-58.

Press, W.H., Flannery, B.R., Teukolsky, S.A., Vetterling, W.T., 1992. Numerical recipes. In: The Art of Scientific Computing. Cambridge University Press, Cambridge.

Prunet, P., Minster, J.F., Ruiz-Pino, D., Dadou, I., 1996. Assimilation of surfaces data in a one-dimensional physicalbiogeochemical model of the surface ocean 1. Method and preliminary results. Global Biogeochemical Cycles 10, 111-138.

Reed, R.K., 1977. On estimating insolation over the ocean. Journal of Physical Oceanography 7, 482-485.

Richardson, K., 1991. Comparison of ${ }^{14} \mathrm{C}$ primary production determinations made by different laboratories. Marine Ecology Progress Series 72, 189-201.

Sarmiento, J.L., Slater, R.D., Fasham, M.J.R., Ducklow, H.W., Toggweiler, J.R., Evans, G.T., 1993. A seasonal three-dimensional ecosystem model of nitrogen cycling in the North Atlantic eophotic zone. Global Geochemical Cycles 10, 139-158.

Schiller, A., 1995. The mean circulation of the Atlantic Ocean north of 30S determined with the adjoint method applied to an ocean general circulation model. Journal of Marine Research 53, 453-497.

Smedstad, O.M., O'Brien, J.J., 1991. Variational data assimilation and parameter estimation in an equatorial Pacific Ocean model. Progress in Oceanography 26, 179-241.

Spitz, Y.H., Moisan, J.R., Abbott, M.R., Richman, J.G., 1998. Data assimilation and a pelagic ecosystem model: parameterization using time series observations. Journal of Marine Systems 16, 51-68.

Steele, J.H., Henderson, E.W., 1992. The role of predation in plankton models. Journal of Plankton Research 14, 157-172.

Thacker, W.C., 1987. Three lectures on fitting numerical model to observations. External Report GKSS 87/E/65, GKSS-Forschungszentrum Geesthacht, GmbH Geesthacht, Germany.

Wagner, F., Lovelace, C., 1971. Phase shift analysis of $\Pi^{-} p \rightarrow K 1^{b}$. Nuclear Physics 25B, 411-427.

Wells, M.L., 1998. A neglected dimension. Nature 391, 530-531. 